\title{
Core Design and Analysis of Axially Heterogeneous Boiling Water Reactor for Burning Transuranium Elements
}

\author{
T. Hino, ${ }^{\mathrm{a} *}$ J. Miwa, ${ }^{\mathrm{a}}$ T. Mitsuyasu, ${ }^{\mathrm{a}}$ Y. Ishii, ${ }^{\mathrm{a}}$ M. Ohtsuka, ${ }^{\mathrm{a}}$ K. Moriya, ${ }^{\mathrm{b}}$ K. Shirvan, ${ }^{\mathrm{c}}$ V. Seker, ${ }^{\mathrm{d}}$ \\ A. Hall, ${ }^{\mathrm{d}}$ T. Downar, ${ }^{\mathrm{d}}$ P. M. Gorman, ${ }^{\mathrm{e}}$ M. Fratoni, ${ }^{\mathrm{e}}$ and E. Greenspan ${ }^{\mathrm{e}}$ \\ ${ }^{a}$ Hitachi, Ltd., Center for Technology Innovation-Energy, Research and Development Group, 7-1-1, Omika-cho, \\ Hitachi-shi, Ibaraki-ken 319-1292, Japan \\ ${ }^{b}$ Hitachi-GE Nuclear Energy, Ltd., 3-1-1, Saiwai-cho, Hitachi-shi, Ibaraki-ken 317-0073, Japan \\ ${ }^{c}$ Massachusetts Institute of Technology, 77 Massachusetts Avenue, Cambridge, Massachusetts 02139 \\ ${ }^{d}$ University of Michigan, 2355 Bonisteel Blvd, Ann Arbor, Michigan 48109-2104 \\ ${ }^{e}$ University of California, Berkeley, Berkeley, California 94720
}

Received January 23, 2017

Accepted for Publication March 25, 2017

\begin{abstract}
The resource-renewable boiling water reactor (RBWR) is an innovative boiling water reactor that has the capability to breed or to burn transuranium elements (TRUs). Core characteristics of the RBWR of the TRU burner type were evaluated by two different core analysis methods. The RBWR core features an axially heterogeneous configuration, which consists of an internal blanket region between two seed regions, to achieve the TRU multi-recycling capability while maintaining a negative void reactivity coefficient. Axial power distribution of the TRU burner core tends to be more heterogeneous because the isotopic composition ratio of fertile TRUs to fissile TRUs becomes larger in the TRU burner-type core than in the breeder-type core and the seed regions need to be axially shorter than that of the breeder-type core. Thus core analysis of the TRU burner-type core is more challenging. A conventional diffusion calculation using nuclear constants prepared by two-dimensional lattice calculations was performed by Hitachi, while the calculation using nuclear constants prepared by three-dimensional calculations and axial discontinuity factors was performed by the University of Michigan to provide a more sophisticated treatment of the axial heterogeneity. Both calculations predicted similar axial power distributions except in the region near the boundary between fuel and plenum. Both calculations also predicted negative void reactivity coefficients throughout the operating cycle. Safety analysis was performed by Massachusetts Institute of Technology for the all-pump trip accident, which was identified as the limiting accident for the RBWR design. The analysis showed the peak cladding temperature remains below the safety limit. Detailed fuel cycle analysis by University of California, Berkeley, showed that per electrical power generated, the RBWR is capable of incinerating TRUs at about twice the rate at which they are produced in typical pressurized water reactors.
\end{abstract}

Keywords - Core analysis, BWR, transmutation.

Note - Some figures may be in color only in the electronic version.

\section{INTRODUCTION}

The resource-renewable boiling water reactor (RBWR) was proposed to provide an alternative solution

*E-mail: tetsushi.hino.kd@hitachi.com to the sodium-cooled fast reactor (SFR) as a long-term energy supply and/or mitigation of the negative environmental impact of transuranium elements (TRUs) as radioactive wastes. ${ }^{1,2}$ The neutron energy spectrum in the RBWR is hardened by the reduction in the hydrogen-touranium ratio $(\mathrm{H} / \mathrm{U})$ from high core voiding, which is a 
major characteristic of the boiling water reactor (BWR), and the RBWR uses the hexagonal tight fuel lattice to enhance the transmutation of ${ }^{238} \mathrm{U}$ to fissile plutonium and fission of nonfissile TRUs such as ${ }^{240} \mathrm{Pu},{ }^{242} \mathrm{Pu}$, and others. This enables the multi-recycling process of both breeding and consuming TRUs. On the other hand, there is a tendency that a harder neutron spectrum in the TRU-loaded core can result in a more positive void reactivity coefficient. The void reactivity coefficient is one of the main safety parameters for light water reactors (LWRs) and must be negative throughout the operating cycle. The RBWR aims to achieve the TRU multirecycling capability under the constraint of the negative void reactivity coefficient by the axially heterogeneous configuration, which consists of an internal blanket region between two seed regions. This configuration successfully works in the LWR core because change in coolant water density leads to relatively large change in neutron leakage probability, which is a negative feedback to the reactivity change when void fraction of coolant increases.

From the viewpoint of core analysis, the axially heterogeneous configuration imposes technical challenges. The issues are related to the scheme of the conventional LWR core analysis method, where nuclear constants such as neutron flux-weighted, node-averaged neutron cross sections are prepared by the fuel lattice calculation. Since the difference in neutron energy spectra between the lattice calculation and the actual core conditions tends to be larger in the axially heterogeneous configuration, the reproducibility of the actual core conditions by the nuclear constants would become more difficult. Furthermore, since the diffusion approximation would be adopted for evaluating the core flux distribution, the rapid change of neutron flux between neighboring nodes, the strong anisotropy of neutron flux distribution, and so on, the axially heterogeneous configuration would degrade accuracy.

These issues motivated Hitachi and the University of Michigan (Michigan) to conduct core analysis using independent analysis methods. This paper describes the latest core specifications and characteristics of the RBWR TRU burner concept. In Sec. II, the system and core specifications of the RBWR are detailed. Section III describes each core analysis method utilized by Hitachi and Michigan and their results. Critical power evaluations and safety analysis of the RBWR are described in Secs. IV and VI, respectively. The comparison between the Hitachi methods and the Michigan and Massachusetts Institute of Technology (MIT) methods are discussed in Sec. V. Section VII compares the fuel cycle of the RBWR and an analogous advanced burner reactor (ABR).

\section{CORE SPECIFICATIONS}

\section{II.A. Overview}

Including the initial plutonium breeder concept, ${ }^{3}$ various core designs have been proposed for the RBWR with different fuel rod configurations optimized for different purposes. Recent designs have focused on TRU management. The RBWR-AC is the break-even reactor that can burn depleted uranium by using TRUs extracted from the spent fuel bundles of LWRs for establishing initial criticality without decreasing the amount of TRUs. The RBWR-TB is the TRU burner, which can fission almost all the TRUs accumulated in the RBWR-ACs and RBWR-TBs, leaving only the minimum critical mass of TRUs, by repeating the recycling while phasing out first the RBWR-ACs and then gradually the RBWR-TBs. The utilization scenario of the RBWR-AC and RBWR-TB are outlined in Fig. 1. After the long-term energy supply from the RBWR-AC, the RBWR-TB is to be introduced to achieve transition away from nuclear power generation while leaving behind almost no TRUs.

The RBWR-TB2 is a modified version of the TRU burner. This core concept was initiated by an Electric Power Research Institute (EPRI)-organized team of three universities in the United States ${ }^{4}$ to compare its core performance values with those of the ABR, which is the SFR having the same purpose. ${ }^{5}$ The RBWR-TB2 is designed to be able to burn TRUs in spent fuels from LWRs. The RBWR-TB2 is assumed to be utilized to control the amount of TRUs during the period while LWRs are being operated as base load power sources (Fig. 2).

Figure 3 shows the reactor pressure vessel (RPV) of the RBWR. The common plant specifications of the RBWR and the latest commercial BWR, the advanced boiling water reactor (ABWR), are listed in Table I. The rated thermal power, electric power, and core pressure are identical for both reactor plants. Figure 4 shows a horizontal cross-sectional view of the RBWR core configuration. The RBWR core is composed of 720 hexagonal fuel bundles and 223 Y-type control rods. The axial configuration uses a parfait core concept in which an internal blanket of depleted uranium oxide is placed between the upper and lower fissile zones of the TRU oxides.

\section{II.B. Core and Fuel Specifications}

A joint research project of MIT, Michigan, the University of California, Berkeley, and Hitachi started 


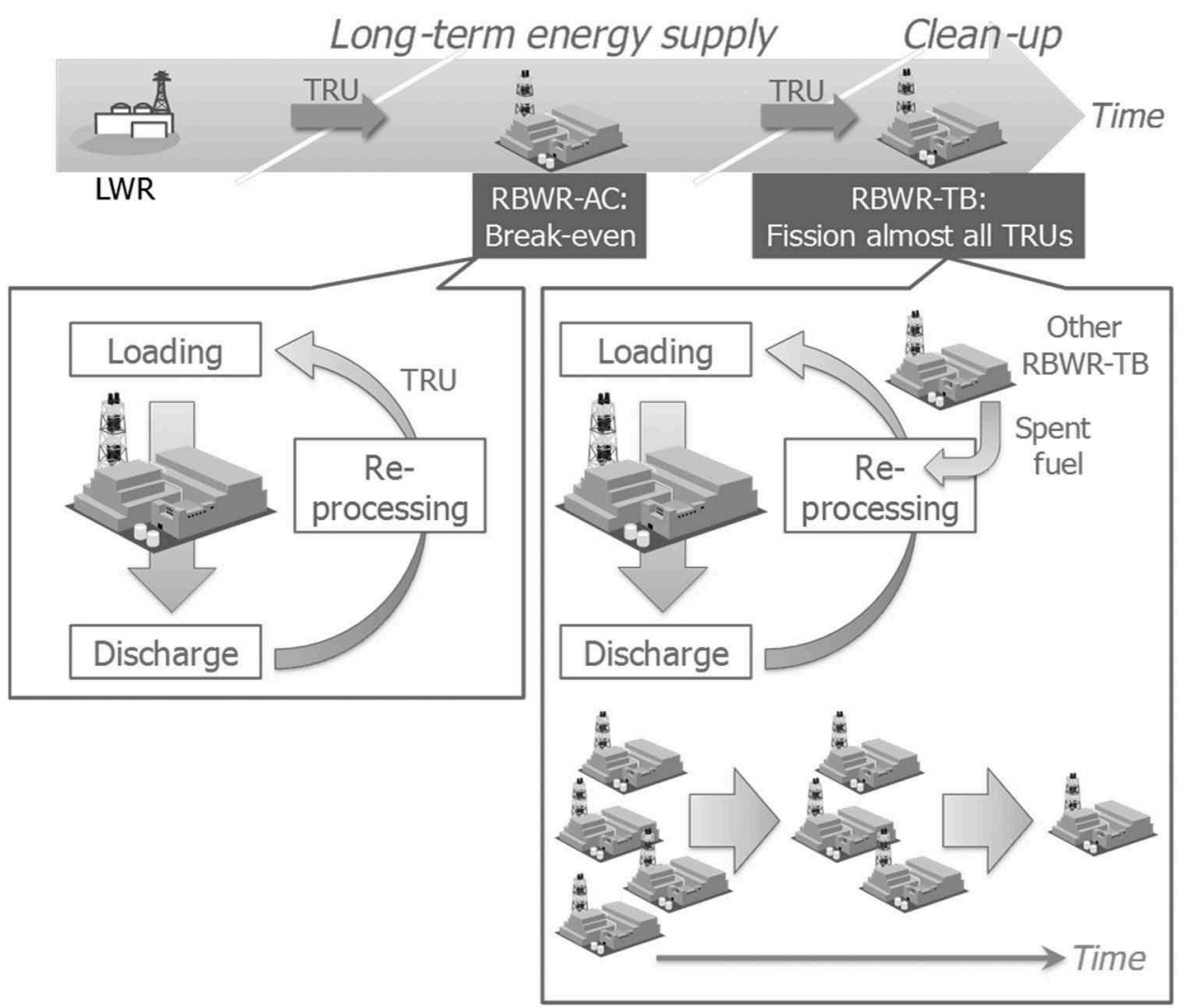

Fig. 1. Utilization scenario of the RBWR-AC and RBWR-TB.

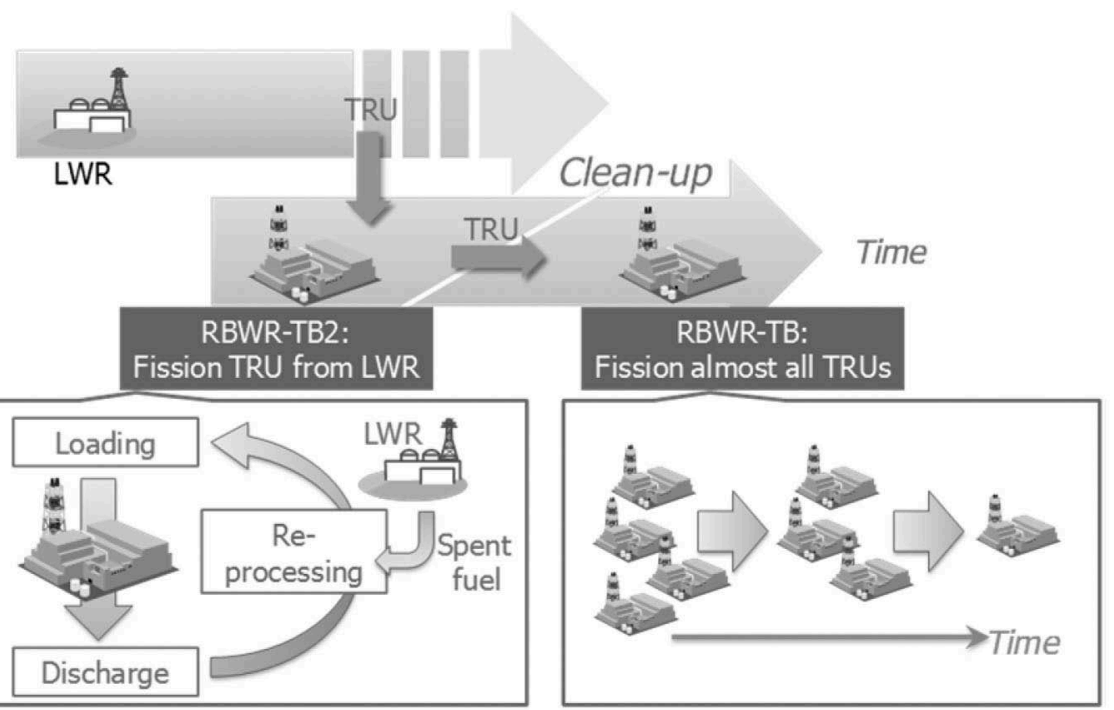

Fig. 2. Utilization scenario of the RBWR-TB2.

in July 2014, focusing on the core analysis of the RBWR-TB2. Hitachi also conducted design and feasibility studies of the fuel assembly and core internal structures. ${ }^{6-8}$
The loading pattern of fuel bundles in the equilibrium core is shown in Fig. 5. A zone loading of fuel bundles was adopted, where burned fuel bundles with the same operation cycle are placed adjacently. The pattern is one-third 


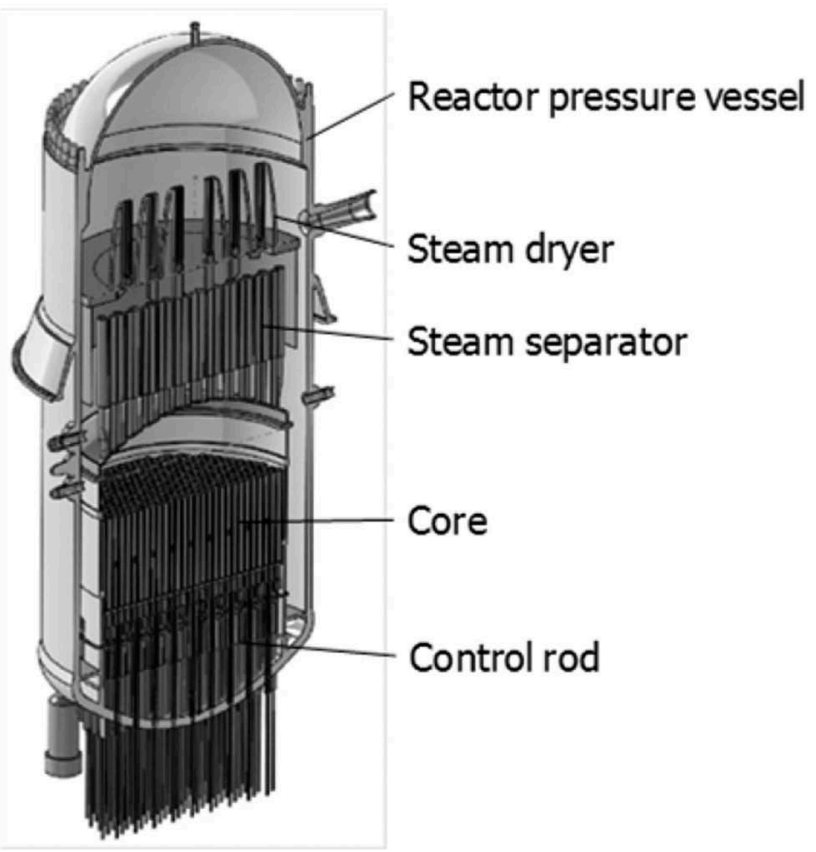

Fig. 3. Reactor pressure vessel of the RBWR.

TABLE I

Plant Specifications

\begin{tabular}{|l|c|c|}
\hline \multicolumn{1}{|c|}{ Item } & RBWR & ABWR \\
\hline Thermal power [MW(thermal)] & 3926 & 3926 \\
Electric power [MW(electric)] & 1356 & 1356 \\
Core pressure (MPa) & 7.1 & 7.1 \\
Number of fuel bundles & 720 & 872 \\
Fuel lattice type & Hexagonal & Square \\
Bundle pitch (mm) & 199 & 155 \\
Number of control rods & 223 & 205 \\
Control rod type & Y-type & Cross shape \\
\hline
\end{tabular}

rotationally symmetric and the zone loading with the optimized control rod insertion pattern helps reduction in the relative radial power, peaking to as low as 1.2.

The latest specifications of the fuel assembly are listed in Table II and its configuration is shown in Fig. 6. The axial configuration is the parfait core, where an internal blanket of depleted uranium oxide is placed between two TRU zones. The void reactivity coefficient is one of the crucial parameters for the safety of BWRs and should be kept negative throughout the burnup cycle. The parfait core configuration contributes to achieving the negative void reactivity coefficient with a cooperation of the axial power shape change caused by the change of void fractions at a transient. The neutron absorber zones are placed above and below the fuel zone (TRU and blanket) to increase the margin to keep the void reactivity coefficient negative. The upper neutron absorber zone is composed of the neutron absorber material surrounding plenums with an outer diameter of $4.8 \mathrm{~mm}$ that are connected to the fuel rod. The neutron absorber material is $\mathrm{B}_{4} \mathrm{C}$ pellets in a sealed tube with an outer diameter of $7.2 \mathrm{~mm}$. Similarly, the lower neutron absorber zone is composed of $\mathrm{B}_{4} \mathrm{C}$ pellets, placed inside the fuel cladding.

An enhanced view of the horizontal cross section of the control rod is shown in Fig. 7. The gap between the control rod and the channel box and the one between the channel boxes are $2.6 \mathrm{~mm}$ and $2.8 \mathrm{~mm}$, respectively. These gaps are determined so as to avoid contacts of the control rods and channel boxes even when the channel box deforms due to the pressure difference between the inside and outside of the channel box and the irradiation creep of the channel box. ${ }^{6-8}$ The span length of the control rod wing is determined so as to place the guide tubes for the nuclear instrumentation system at the side of the control rods. The

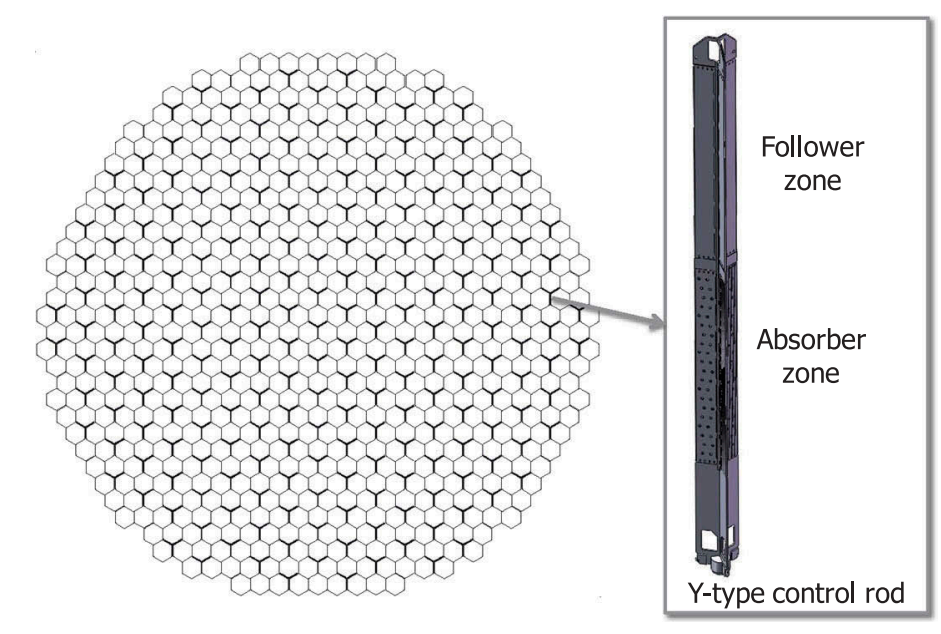

Fig. 4. Horizontal cross-sectional view of the RBWR core configuration. 


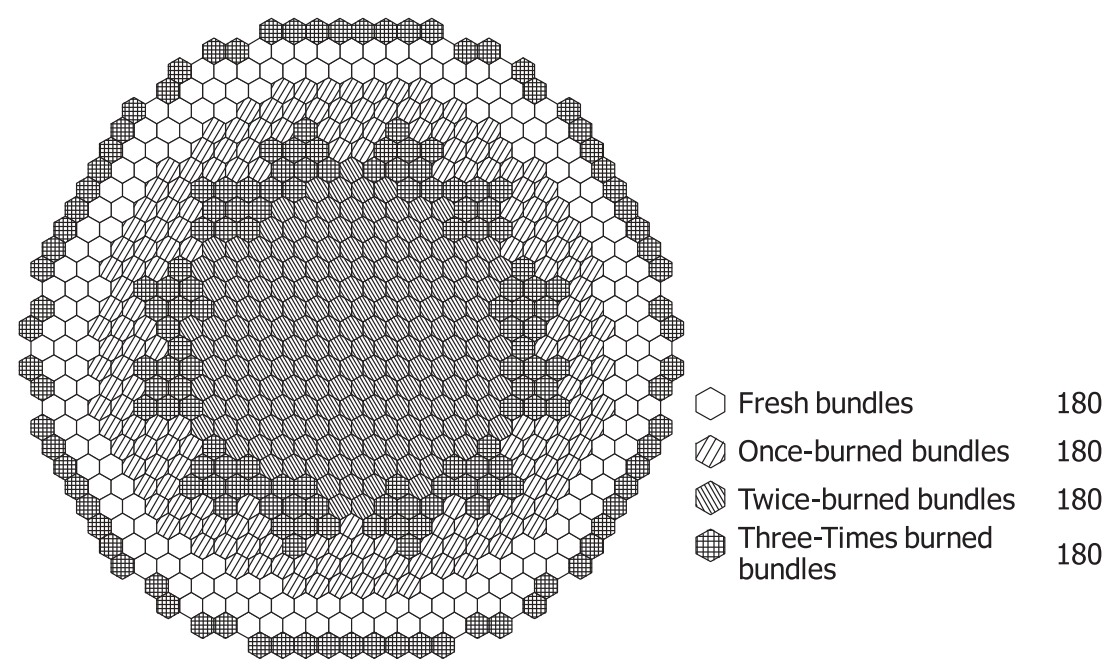

Fig. 5. Core loading pattern.

TABLE II

Fuel Assembly Specifications

\begin{tabular}{|l|c|}
\hline \multicolumn{1}{|c|}{ Item } & Value \\
\hline Channel box inner width (mm) & 185.6 \\
Channel box thickness (mm) & 3.0 \\
Cladding outer diameter (mm) & 7.2 \\
Cladding thickness (mm) & 0.6 \\
Cladding material & Zircaloy \\
Fuel rod pitch (mm) & 9.1 \\
Number of fuel rods & 397 \\
Plenum outer diameter (mm) & 4.8 \\
Outer diameter of upper neutron & 7.2 \\
absorber (mm) & 7.2 \\
Outer diameter of lower neutron & \\
absorber (mm) & \\
\hline
\end{tabular}

feasibility of a nuclear instrumentation system with the thin neutron detectors is being investigated. So far, it has been found that the nuclear instrumentation system has a capability for rod block monitoring. ${ }^{9}$

For the neutron absorber for the control rod, the $\mathrm{B}_{4} \mathrm{C}$ pellet with $90 \%$ enriched ${ }^{10} \mathrm{~B}$ is assumed. The follower zone consists of graphite covered with a stainless steel sheath. The follower zone remains at the fuel active region when the control rod is fully withdrawn in order to minimize the amount of water between the fuel assemblies.

The TRU enrichment distributions are shown in Fig. 8. Fuel rods in outer layers have lower enrichments to reduce the maximum relative rod power. The pellet density is assumed based on the conventional uraniumplutonium mixed fuel, which is dependent on the plutonium composition.

\section{CORE ANALYSIS METHOD}

\section{III.A. Hitachi Method}

\section{III.A.1. Overview}

The Hitachi core analysis methods are basically the same as the conventional core analysis scheme used for LRWs. Group constants of 12 energy groups for the core neutronic calculation were generated from the 190-energy-groups library for the horizontal cross section of the fuel bundle lattice by the Monte Carlo calculation code, VMONT (Ref. 10). The 12 energy group boundaries are shown in Table III. They were based on a few group energy boundaries from experiences in current BWR core analysis, and some boundaries were added in the resonance region. In the burnup calculation, 45 actinides from ${ }^{228} \mathrm{Th}$ to ${ }^{253} \mathrm{Es}$ and 84 fission products (FPs) (83 nuclides treated explicitly and one lumped fission product) were treated. Conditions for burnup and branch calculations are shown in Tables IV and V, respectively. The burnup calculations were done by assuming void fractions of $0 \%, 30 \%, 55 \%$, and $80 \%$, respectively. The highest void fraction of $80 \%$ covered the void fraction at the exit of the active fuel region of the bundle with the maximum power. Branch calculations were conducted at each exposure step of each burnup calculation. Branch calculations by changing temperatures of blanket and TRU zones with $100 \mathrm{~K}$ steps were done to evaluate Doppler coefficient. Branch calculations with temperature of $293 \mathrm{~K}$ for blanket and TRU zones were also done to prepare group constants for evaluation of the cold shutdown margin. 


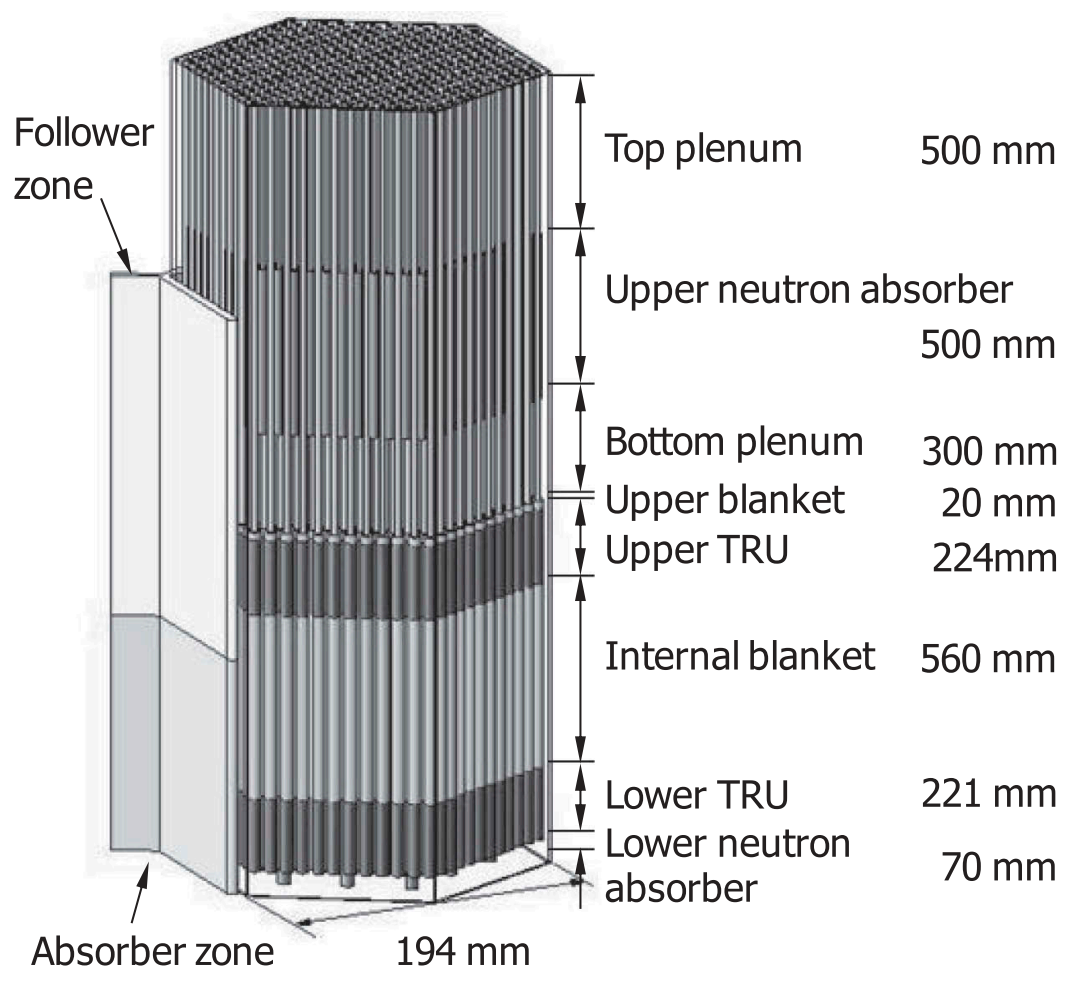

Fig. 6. Fuel assembly configuration.

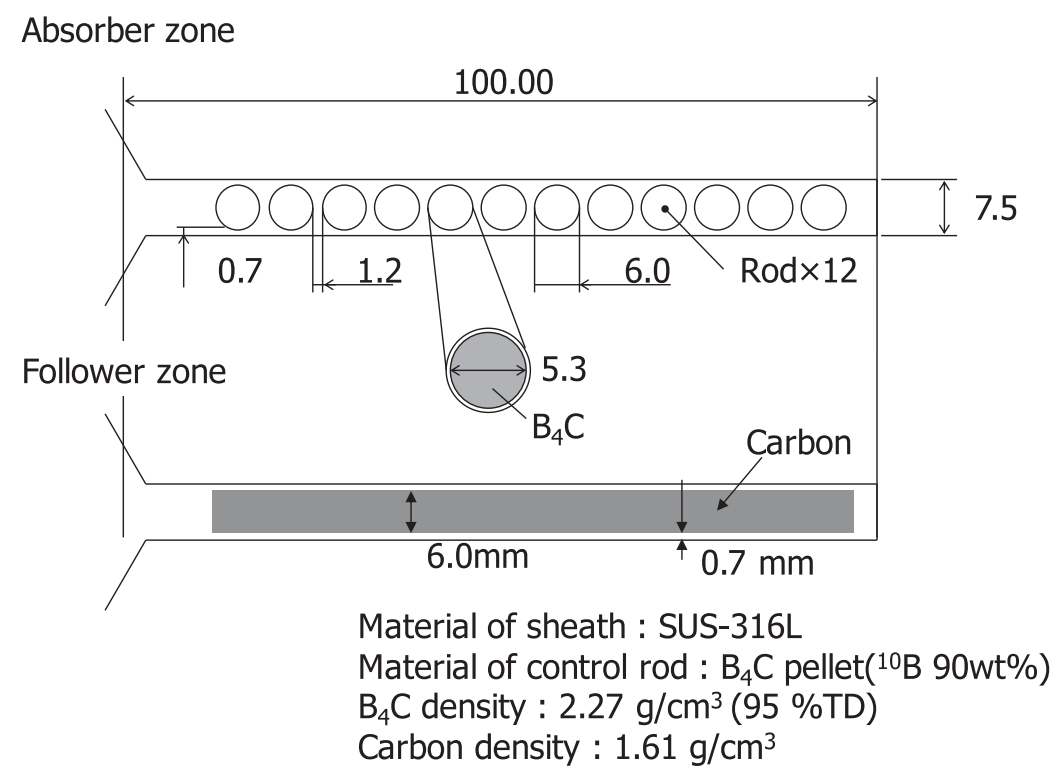

Fig. 7. Horizontal configuration of the control rod.

In the core neutronic calculation, the 12 energy group, three-dimensional (3D) neutron flux was obtained by solving the diffusion equation using CITATION (Ref. 11), with one mesh for each fuel lattice in the horizontal direction and 34 meshes for the active fuel region in the axial direction.
In the thermal-hydraulic calculation, the in-channel coolant flow rate, the two-phase flow pressure drop, and the axial void fraction distribution were calculated based on the power distribution obtained by the core neutronic calculation, so that the pressure drops between fuel bundles were balanced. The core neutronic calculation and 


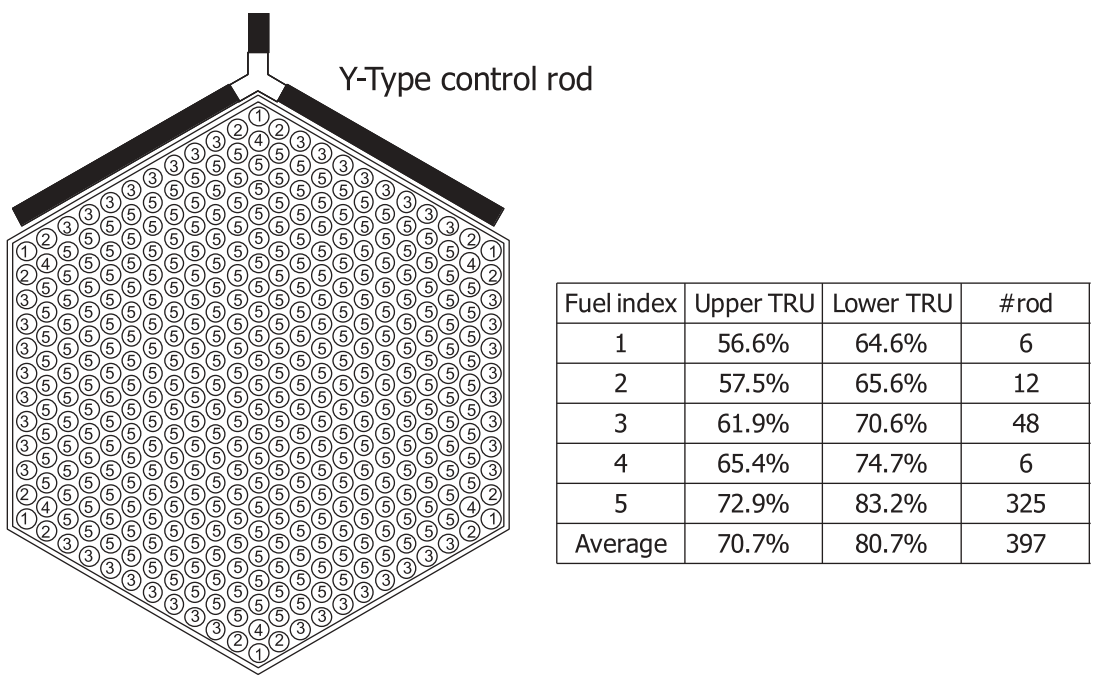

Fig. 8. TRU enrichment distribution.

TABLE III

Energy Group Boundaries for Core Neutronic Calculation

\begin{tabular}{|c|c|c|c|}
\hline Group & $\begin{array}{c}\text { Upper } \\
\text { Energy }(\mathrm{eV})\end{array}$ & Group & $\begin{array}{c}\text { Upper } \\
\text { Energy }(\mathrm{eV})\end{array}$ \\
\hline 1 & $1.0 \times 10^{7}$ & 7 & $4.09 \times 10^{4}$ \\
2 & $3.68 \times 10^{6}$ & 8 & $5.53 \times 10^{3}$ \\
3 & $2.23 \times 10^{6}$ & 9 & $1.3 \times 10^{2}$ \\
4 & $1.35 \times 10^{6}$ & 10 & 3.92 \\
5 & $4.98 \times 10^{5}$ & 11 & 1.45 \\
6 & $1.83 \times 10^{5}$ & 12 & 0.625 \\
\hline
\end{tabular}

TABLE IV

Burnup Calculation Conditions

\begin{tabular}{|c|c|c|}
\hline $\begin{array}{c}\text { Void } \\
\text { Fraction (\%) }\end{array}$ & $\begin{array}{c}\text { Control Rod } \\
\text { State }^{\mathrm{a}}\end{array}$ & $\begin{array}{c}\text { Fuel Temperature (K), } \\
\text { Blanket/TRU }\end{array}$ \\
\hline 0 & & \\
30 & N/B & $723 / 1000$ \\
55 & & \\
80 & & \\
\hline
\end{tabular}

${ }^{\mathrm{a} N}$ /B: Control rod fully withdrawn.

the thermal-hydraulic calculation were iterated until the power distribution and in-channel coolant flow distribution converged.

\section{III.A.2. Neutronics}

One of major issues in the conventional core analysis scheme is the difference in neutron energy spectra
TABLE V

Branch Calculation Conditions

\begin{tabular}{|l|c|c|}
\hline Void Fraction (\%) & $\begin{array}{c}\text { Control } \\
\text { Rod State }^{\mathrm{a}}\end{array}$ & $\begin{array}{c}\text { Fuel Temperature (K), } \\
\text { Blanket/TRU }\end{array}$ \\
\hline \multirow{2}{*}{$0,30,55,80,100$} & N/B, W/B & $723 / 1000$ \\
\cline { 2 - 3 } & N/B & $\begin{array}{c}300 \text { to } 1000 / 700 \text { to } 2000 \\
(100 \mathrm{~K} \text { steps })\end{array}$ \\
\hline 0 & N/B, W/B & 293 \\
\hline
\end{tabular}

${ }^{\mathrm{a}} \mathrm{N} / \mathrm{B}$ : Control rod fully withdrawn. W/B: Control rod fully inserted.

between the two-dimensional (2D) infinite lattice calculation for preparing group energy constants and the physical core configuration. In the physical core configuration, a neutron spectrum of a fuel bundle is affected by the incoming neutron current from the neighboring fuel bundles, which has different neutron spectra. The same kind of issue would emerge regarding the axial heterogeneous configuration of the RBWR core. The Hitachi method takes care of the neutron spectra in the upper blanket region, which is affected by the reflector region above the upper blanket region, by introducing the historical void correction method. The historical void fraction is the burnup-averaged void fraction and is used as an index to interpolate group energy constants from the prepared ones by the lattice calculations. The neutron spectrum in the upper blanket region would be softened by the incoming neutron current, which has a softer neutron spectrum than the upper blanket region. This condition is represented by interpolating group energy constants of the 
upper blanket region using the historical void fraction as an index, corrected as follows:

$$
V_{k}=V_{k \min }+\frac{\phi_{k}^{12}-\phi_{k \min }^{12}}{\phi_{k \max }^{12}-\phi_{k \min }^{12}} \cdot\left(V_{k \text { max }}^{\prime}-V_{k \min }\right),
$$

where

$$
\begin{aligned}
V_{k}, \phi_{k}^{12}= & \text { corrected historical void fraction and } \\
& \text { neutron flux in group } 12 \text { for node } k \text { in } \\
& \text { the upper blanket region } \\
V_{k \text { min }}, \phi_{k \text { min }}^{12}= & \text { calculated historical void fraction } \\
& \text { and neutron flux in group } 12 \text { for the } \\
& \text { bottom node in the upper blanket } \\
& \text { region } \\
\phi_{k \max }^{12}= & \text { neutron flux in group } 12 \text { for the top } \\
& \text { node in the upper blanket region } \\
V_{k \max }^{\prime}= & \text { assumed historical void fraction for } \\
& \text { the top node in the upper blanket } \\
& \text { region. }
\end{aligned}
$$

$V_{k \text { min }}$ is calculated with the instantaneous void fraction of the corresponding node at an exposure step ie, $v_{k \min }^{i e}$ as

$$
V_{k \min }=\sum_{i e}\left(v_{k \min }^{i e} \Delta E_{k \min }^{i e}\right) / \sum_{i e} \Delta E_{k \min }^{i e},
$$

where $\Delta E_{k \min }^{i e}$ is the exposure increment of the corresponding node at the exposure step ie, and the summation is taken from the beginning of the cycle to the current step.

The correction just described provides a simple correlation between the effective historical void fraction and the neutron thermal flux. $V_{k \max }^{\prime}$ is an arbitrary parameter that was determined so that the power of the top node in the upper blanket region is not unphysical. In this study $V_{k \max }^{\prime}$ was set to 0.5 while the actual calculated historical void fraction of the top node in the upper blanket region was about 0.7 . Since the height of the upper blanket region is $20 \mathrm{~mm}$ compared to the $1025 \mathrm{~mm}$ core height, the change in assumed $V_{k \max }^{\prime}$ does not have large impact on the overall core characteristics, such as neutron multiplication factors and mass balance. On the other hand, evaluation of the properties strongly depends on the axial power distribution, such as the thermal margin and the void reactivity coefficient. One of the motivations to evaluate the RBWR core characteristics separately by Hitachi and Michigan methods was to obtain confidence in the prediction of the core power distribution and reactivity coefficients.

\section{III.A.3. Thermal Hydraulics}

The thermal-hydraulic models for RBWR core are based on the one-dimensional (1D) parallel channel model. Each channel (= fuel bundle) flow is calculated so as to have the same pressure drops for the channels. To calculate the channel pressure drop, the void fraction is evaluated and then also used for the core neutronics calculation.

Calculation models are basically the same as the models described in Ref. 12. Flow quality, which is used for calculations of void fraction and two-phase flow pressure drop, is evaluated by Zuber's profile-fit model. Subcooled boiling is considered in the flow quality calculation with initiating enthalpy evaluated by Levy's correlation. The void fraction is evaluated with the void-quality correlation by the Zuber-Findlay drift flux model.

Pressure drop of the channel is evaluated by

$$
\Delta P=\Delta P_{f r}+\Delta P_{l o c}+\Delta P_{s h}+\Delta P_{a c c},
$$

where

$$
\begin{aligned}
\Delta P & =\text { total pressure drop }(\mathrm{Pa}) \\
\Delta P_{f r} & =\text { frictional pressure drop }(\mathrm{Pa}) \\
\Delta P_{l o c} & =\text { local pressure drop }(\mathrm{Pa}) \\
\Delta P_{s h} & =\text { elevation pressure drop (static head) }(\mathrm{Pa}) \\
\Delta P_{a c c} & =\text { acceleration pressure drop }(\mathrm{Pa}) .
\end{aligned}
$$

Frictional pressure drop. The frictional pressure drop is expressed as

$$
\Delta P_{f r}=\sum_{k=1}^{N}\left(\frac{f_{k} \cdot \Delta z_{k}}{2 D_{h, k}} \frac{W_{k}^{2}}{\rho_{\ell, k} \cdot A_{k}^{2}} \phi_{F, k}^{2}\right)
$$

where

$$
\begin{aligned}
D_{h, k}= & \text { hydraulic diameter }(\mathrm{m}) \\
f_{k}= & \text { single-phase friction factor }(-) \\
\rho_{\ell, k}= & \text { water density }\left(\mathrm{kg} / \mathrm{m}^{3}\right) \\
\phi_{F, k}^{2}= & \text { two-phase friction multiplier due to } \\
& \text { Martinelli-Nelson correlation }(-) \\
W_{k}= & \text { coolant flow rate }(\mathrm{kg} / \mathrm{s}) \\
A_{k}= & \text { coolant cross-sectional flow area }\left(\mathrm{m}^{2}\right) \\
\Delta z_{k}= & \text { nodal length }(\mathrm{m})
\end{aligned}
$$




$$
\begin{aligned}
N & =\text { total number of nodes } \\
k & =\text { nodal index. }
\end{aligned}
$$

Local pressure drop: Each irreversible local loss is expressed as

$$
\Delta P_{l o c, i}=\frac{K_{i}}{2} \frac{W_{i}^{2}}{\rho_{\ell, i} \cdot A_{i}^{2}} \phi_{L, i}^{2}
$$

and

$$
\phi_{L, i}^{2}=1+\left(\frac{\rho_{\ell, i}}{\rho_{g, i}}-1\right) X_{i},
$$

where

$$
\begin{aligned}
K_{i}= & i^{\prime} \text { th local loss coefficient }(-) \\
\phi_{L, k}^{2}= & \text { two-phase local loss multiplier }(-) \\
\rho_{\ell, i}= & \text { water density }\left(\mathrm{kg} / \mathrm{m}^{3}\right) \\
\rho_{g, i}= & \text { steam density }\left(\mathrm{kg} / \mathrm{m}^{3}\right) \\
W_{i}= & \text { corresponding coolant flow rate }(\mathrm{kg} / \mathrm{s}) \\
A_{i}= & \text { corresponding coolant cross-sectional flow } \\
& \text { area }\left(\mathrm{m}^{2}\right) \\
X_{i}= & \text { flow quality }(-) \\
i= & \text { local loss index. }
\end{aligned}
$$

The local loss is evaluated at the channel inlet orifice, lower tie plate, upper tie plate, and spacers.

Elevation pressure drop. The elevation pressure drop is expressed by

$$
\Delta P_{s h}=\sum_{k=1}^{N}\left(\bar{\rho}_{k} \cdot g \cdot \Delta z_{k}\right)
$$

where

$$
\begin{aligned}
\bar{\rho}_{k}=\rho_{\ell, k}\left(1-\alpha_{k}\right)+\rho_{g, k} \alpha_{k}= & \text { average density for } \\
& \text { node } k\left(\mathrm{~kg} / \mathrm{m}^{3}\right) \\
\alpha_{k}= & \text { average void fraction } \\
& \text { for node } k(-) \\
g= & \text { acceleration of gravity } \\
& \left(\mathrm{m} / \mathrm{s}^{2}\right) \\
\Delta z_{k}= & \text { nodal length }(\mathrm{m}) \\
N= & \text { total number of nodes } \\
k= & \text { nodal index. }
\end{aligned}
$$

Acceleration pressure drop. ${ }^{12}$ The acceleration pressure drop includes pressure changes resulting from fluid density changes and pressure changes resulting from flow area changes. The acceleration pressure drop caused by change in fluid density is expressed as

$$
\Delta P_{a c c, 1}=\frac{W^{2}}{A^{2}}\left(\frac{1}{\rho_{H, 2}}-\frac{1}{\rho_{H, 1}}\right),
$$

where

$$
\frac{1}{\rho_{H}}=\frac{X}{\rho_{g}}+\frac{(1-X)}{\rho_{\ell}},
$$

and where

$$
\begin{aligned}
\rho_{H, 1} & =\text { inlet homogeneous density } \\
\rho_{H, 2} & =\text { outlet homogeneous density } \\
W & =\text { coolant flow rate }(\mathrm{kg} / \mathrm{s}) \\
A & =\text { flow area }\left(\mathrm{m}^{2}\right) \\
X & =\text { flow quality }(-) \\
\rho_{g} & =\text { steam density }\left(\mathrm{kg} / \mathrm{m}^{3}\right) \\
\rho_{\ell} & =\text { water density }\left(\mathrm{kg} / \mathrm{m}^{3}\right) .
\end{aligned}
$$

The reversible pressure change resulting from flow area changes is expressed as

$$
\Delta P_{r e v}=\frac{W_{1}^{2}}{2 A_{1}^{2}} \frac{\rho_{H}}{\rho_{k E}^{2}}\left(1-\omega^{2}\right) .
$$

The irreversible pressure loss resulting from flow area changes is expressed as

$$
\begin{gathered}
\Delta P_{\text {irrev }}=\frac{W_{1}^{2}}{2 A_{1}^{2} \rho_{\ell}}\left[\frac{\rho_{H, 1}+\rho_{H, 2}}{2}\left(\frac{\rho_{\ell}}{\rho_{k E, 1^{2}}}-\frac{\rho_{\ell} \omega^{2}}{\rho_{k E, 2}{ }^{2}}\right)\right. \\
\left.+2 \rho_{\ell}\left(\frac{\omega^{2}}{\rho_{M, 2}}-\frac{\omega}{\rho_{M, 1}}\right)\right], \\
\frac{1}{\rho_{k E}{ }^{2}}=\frac{(1-X)^{3}}{\rho_{\ell}^{2}(1-\alpha)^{2}}+\frac{X^{3}}{\rho_{g}^{2} \alpha^{2}},
\end{gathered}
$$

and

$$
\frac{1}{\rho_{M}}=\frac{(1-X)^{2}}{\rho_{\ell}(1-\alpha)}+\frac{X^{2}}{\rho_{g} \alpha},
$$

where 


$$
\begin{aligned}
W & =\text { coolant flow rate }(\mathrm{kg} / \mathrm{s}) \\
A_{1} & =\text { inlet flow area }\left(\mathrm{m}^{2}\right) \\
A_{2} & =\text { outlet flow area }\left(\mathrm{m}^{2}\right) \\
X & =\text { flow quality }(-) \\
\rho_{g} & =\text { steam density }\left(\mathrm{kg} / \mathrm{m}^{3}\right) \\
\rho_{\ell} & =\text { water density }\left(\mathrm{kg} / \mathrm{m}^{3}\right) \\
\omega=\frac{A_{1}}{A_{2}} & =\text { ratio of the inlet to the outlet flow area }(-) .
\end{aligned}
$$

\section{III.A.4. Core Modeling}

In the radial direction a hexagonal node was used to represent each fuel lattice as shown in Fig. 5. Two layers of radial reflector nodes, whose group constants are evaluated as saturated water, were placed outside of the core (not shown in Fig. 5). Outside the radial reflectors was vacuum condition. The axial modeling for the simulations is shown in Fig. 9. Above the upper plenum zone and under the lower reflector zone are vacuum conditions. The number of nodes/ mesh for each axial zone is summarized in Table VI. The number of nodes for the upper neutron absorber, bottom plenum, upper TRU, and lower neutron absorber zones were set relatively larger to represent rapid changes in neutron flux and energy spectrum in these zones.

The thermal-hydraulic calculation evaluated each fuel channel with the model described in Sec. III.A.3.

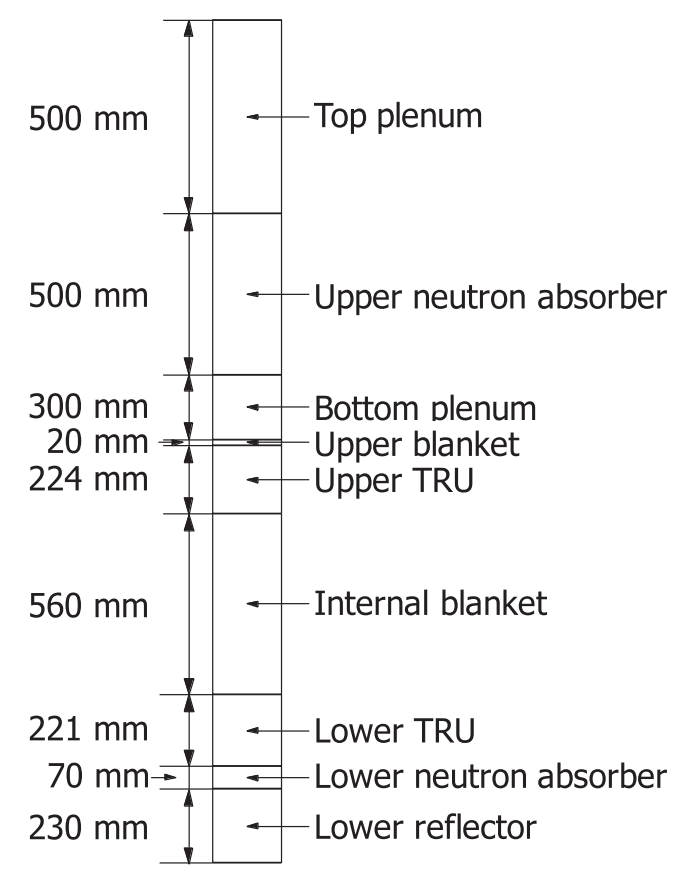

Fig. 9. Axial modeling.
TABLE VI

Axial Node Segmentation in the Hitachi Method

\begin{tabular}{|l|c|c|}
\hline \multicolumn{1}{|c|}{ Zone } & Height $(\mathrm{mm})$ & $\begin{array}{c}\text { Number } \\
\text { of Mesh }\end{array}$ \\
\hline Top plenum & 500 & 1 \\
Upper neutron absorber & 500 & 25 \\
Bottom plenum & 300 & 25 \\
Upper blanket & 20 & 10 \\
Upper TRU & 224 & 8 \\
Internal blanket & 560 & 8 \\
Lower TRU & 221 & 8 \\
Lower neutron absorber & 70 & 20 \\
Lower reflector & 230 & 10 \\
\hline
\end{tabular}

The control rod pattern for the equilibrium cycle is shown in Fig. 10.

\section{III.B. Method of University of Michigan Method}

\section{III.B.1. Overview}

The core analysis methods used at Michigan also consist of a multistep calculation process, which is similar to the conventional LWR analysis method. ${ }^{13}$ For the first step, group constants are generated for a single 3D fuel assembly using the continuous energy Monte Carlo code Serpent. ${ }^{14}$ Group constants are generated at all anticipated temperature and fluid conditions in the reactor and are then processed and converted into a PMAXS format. ${ }^{15}$ Conditions for burnup and branch calculations are shown in Tables VII and VIII, respectively. Bundle-averaged void fractions in the burnup calculation of $57 \%, 33 \%$, and $68 \%$ correspond to the reference, high, and low coolant flow conditions, respectively. This range of void fraction covers the actual range of bundle-averaged void fractions in the core calculation from around $40 \%$ to $60 \%$. Branch calculations were done from each exposure step of the reference burnup calculation with void fraction of $57 \%$. The branch calculation included conditions with void fractions of $0 \%$ and $100 \%$ for the entire bundle configuration.

To evaluate the axial void distributions, at first, an initial set of 2D cross sections was generated by Serpent and used in a single assembly calculation by the $3 \mathrm{D}$ reactor core simulator PARCS (Purdue Advanced Reactor Core Simulator $)^{16}$ coupled with the thermalhydraulic code PATHS (Ref. 17) to generate an initial 

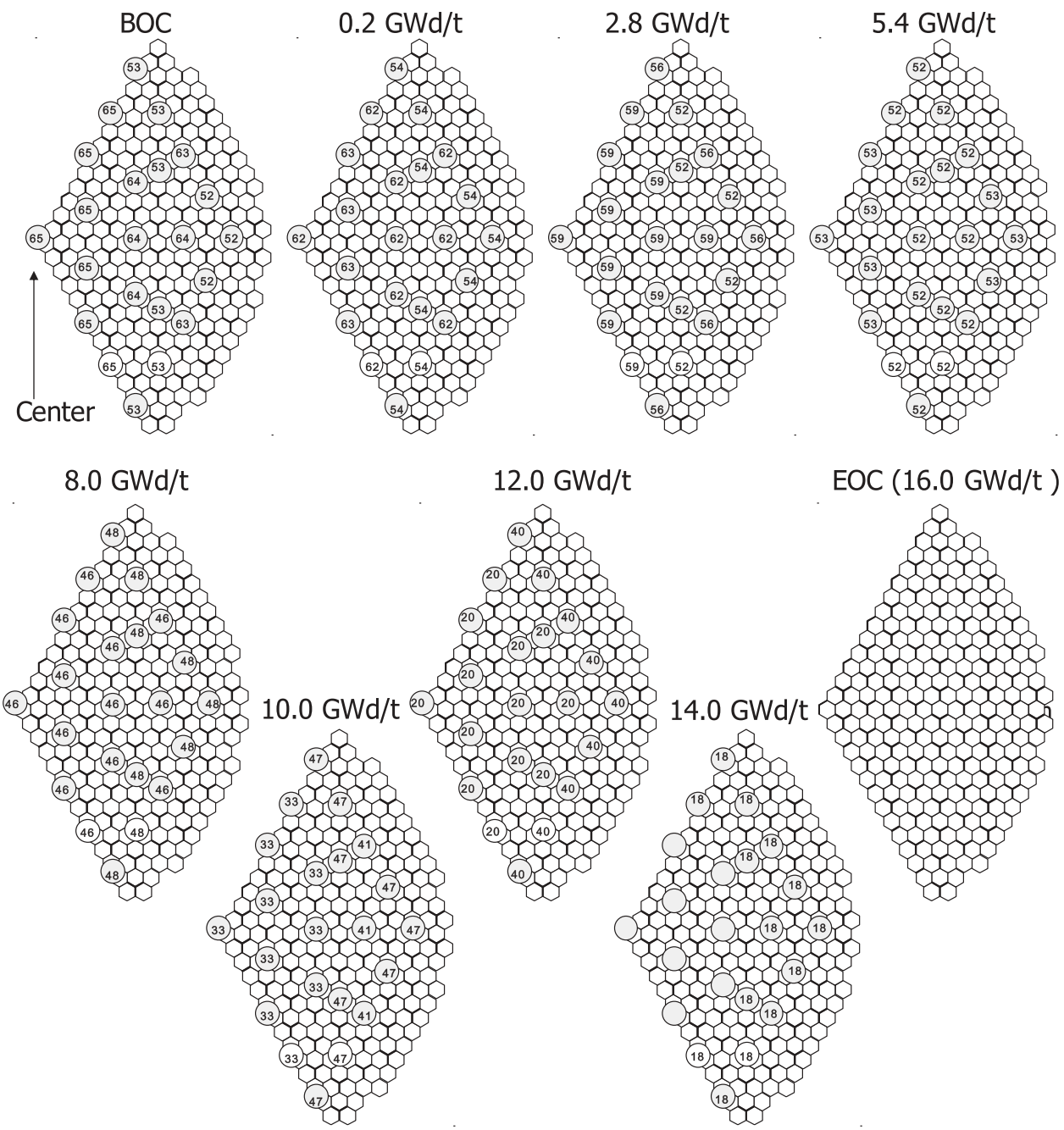

(N) Control rod Insertion depth ( full insertion : 65 )

Fig. 10. Control rod pattern.

TABLE VII

Burnup Calculation Conditions

\begin{tabular}{|c|c|c|}
\hline $\begin{array}{c}\text { Bundle-Averaged } \\
\text { Void Fraction (\%) }\end{array}$ & $\begin{array}{c}\text { Fuel } \\
\text { Control Rod }_{\text {State }^{\mathrm{a}}}\end{array}$ & $\begin{array}{c}\text { Temperature (K), } \\
\text { Blanket/TRU }\end{array}$ \\
\hline 33 & N/B & \\
57 & $600 / 900$ \\
68 & W/B & \\
\hline 57 & \\
\hline
\end{tabular}

${ }^{a}$ N/B: Control rod fully withdrawn. W/B: Control rod fully inserted.

guess for the void distribution. This void distribution was then placed within a 3D Serpent calculation to generate a set of $3 \mathrm{D}$ cross sections. Using these group constants, a second set of coupled PARCS/PATHS simulations, for a single assembly, was performed to generate the final void distribution to be used for each burnup and branch calculation. This technique provides a coolant axial void distribution that is closer to that of the physical system compared to a uniform distribution.

Using these tabulated group constants, PARCS is coupled to PATHS to evaluate core characteristics in equilibrium cycle. The hexagonal nodal diffusion kernel is used in PARCS, which is based on the triangular polynomial expansion method (TPEN), to solve for the few group fluxes in the radial direction. The axial flux is solved using the 1D nodal expansion method (NEM) and coupled to the radial solution using the traditional transverse leakage approximation. The codes are coupled with PARCS providing the nodewise powers to PATHS, while PATHS provides 
TABLE VIII

Branch Calculation Conditions

\begin{tabular}{|c|c|c|}
\hline $\begin{array}{c}\text { Bundle-Averaged } \\
\text { Void Fraction } \\
(\%)\end{array}$ & $\begin{array}{c}\text { Control Rod } \\
\text { State }^{\mathrm{a}}\end{array}$ & $\begin{array}{c}\text { Fuel } \\
\text { Temperature (K), } \\
\text { Blanket/TRU }\end{array}$ \\
\hline 57 & W/B & \\
\cline { 1 - 2 } 100 & N/B & $600 / 900$ \\
68 & & \\
33 & N/B & $500 / 600$ \\
0 & & $1200 / 1200$ \\
\hline 57 & & \\
\hline
\end{tabular}

${ }^{\mathrm{a} N} / \mathrm{B}$ : Control rod fully withdrawn. W/B: Control rod fully inserted.

PARCS with the fuel temperature, coolant density, and coolant temperature. The two codes iterate until a converged solution is achieved. Calculation of the equilibrium cycle of the RBWR is an iterative process that consists of depleting the full core and then shuffling the fuel bundles. The process is repeated until a desired maximum burnup difference between fuel recycles is met. Depletion was performed using the same control rod movement and fuel shuffling pattern as those in the Hitachi analysis.

\section{III.B.2. Neutronics}

The Michigan method was developed specifically to account for the influence of the axially heterogeneous configuration of the parfait core on the few group cross sections and the core analysis. ${ }^{13}$ As mentioned in Sec. III.A.2, one of the issues that might cause uncertainty in the conventional core analysis using group constants generated with 2D calculations is the difference in neutron energy spectrum between the $2 \mathrm{D}$ calculation and the physical $3 \mathrm{D}$ core configuration. In order to better treat this effect, the Michigan method prepares group constants using a 3D single assembly calculation performed with the Serpent Monte Carlo code. The number of energy groups and their energy boundaries are the same as those used by Hitachi. The axial void distribution for this calculation is obtained by the single assembly calculation using PARCS coupled with the PATHS thermal-hydraulic code, which is described in this section.
Another issue caused by the heterogeneous core configuration is the difficulty in accurately modeling the rapid change of the neutron flux level using a conventional diffusion calculation. For this issue the Michigan method introduces the axial discontinuity factors ${ }^{13}$ (ZDFs). For a given axial interface, a ZDF is defined as the ratio of the heterogeneous surface flux to the homogeneous surface flux:

$$
f=\frac{\phi_{s, i, g}^{\text {het }}}{\phi_{s, i, g}^{\text {hom }}},
$$

where

$$
\begin{aligned}
f & =\text { axial discontinuity factor } \\
\phi_{s, i, g}^{\text {het }} & =\text { heterogeneous surface flux } \\
\phi_{s, i, g}^{\text {hom }} & =\text { homogeneous surface flux } \\
i & =\text { index for node } \\
g & =\text { index for energy group. }
\end{aligned}
$$

The heterogeneous surface flux is approximated using the partial currents from Serpent:

$$
\phi_{s, i, g}^{h e t}=2\left(J_{i, g}^{+}+J_{i, g}^{-}\right)
$$

where $J_{i, g}^{+}$and $J_{i, g}^{-}$are the partial incoming and outgoing currents for a given surface.

The homogeneous surface flux is solved using the same method as PARCS (NEM for this case) in order to reproduce the Monte Carlo solution. The NEM approximates the flux solution within each mesh region using a fourth-order Legendre polynomial:

$$
\vec{\phi}(\xi)=\sum_{i=0}^{4} \vec{a}_{i} P_{i}(\xi)
$$

where $\vec{a}_{i}$ are the expansion coefficients and $P_{i}(\xi)$ are the Legendre polynomials.

The five coefficients associated with the flux expansion derive from the heterogeneous cell average flux, the net currents on the top and bottom surfaces, and two weighted residual equations. The homogeneous surface fluxes for the top and bottom surfaces are found using the evaluated coefficients:

$$
\vec{a}_{0}=\bar{\phi},
$$




$$
\begin{gathered}
\left(\overline{\bar{A}}+\frac{5 \overline{\bar{D}}}{2 h^{2}}\right) \vec{a}_{1}=-\frac{5}{4 h}\left(\vec{J}^{B}+\vec{J}^{T}\right), \\
\left(\overline{\bar{A}}+\frac{21 \overline{\bar{D}}}{2 h^{2}}\right) \vec{a}_{2}=-\frac{7}{4 h}\left(\vec{J}^{B}-\vec{J}^{T}\right), \\
\vec{a}_{3}=-\frac{h}{12 \overline{\bar{D}}}\left(\vec{J}^{B}+\vec{J}^{T}\right)-\frac{1}{6} \vec{a}_{1}, \\
\vec{a}_{4}=\frac{h}{20 \overline{\bar{D}}}\left(\vec{J}^{B}-\vec{J}^{T}\right)-\frac{3}{10} \vec{a}_{2} \\
\vec{\phi}_{i, g}^{B, \text { Hom }}=\vec{a}_{0}-\vec{a}_{1}+\vec{a}_{2}-\vec{a}_{3}+\vec{a}_{4}
\end{gathered}
$$

and

$$
\vec{\phi}_{i, g}^{T, H o m}=\vec{a}_{0}+\vec{a}_{1}+\vec{a}_{2}+\vec{a}_{3}+\vec{a}_{4}
$$

where

$$
\begin{aligned}
\overline{\bar{A}}= & \text { matrix consisting of the diagonal matrix of the } \\
& \text { groupwise total cross section, the full matrix } \\
& \text { of the group-to-group scattering cross section, } \\
& \text { the eigenvalue, the vector of the groupwise } \\
& \text { fission spectrum, and the transposed vector of } \\
& \text { the groupwise product of the average number } \\
& \text { of fission neutrons produced per fission and } \\
& \text { the fission cross section } \\
\overline{\bar{D}}= & \text { diagonal matrix of the groupwise diffusion } \\
& \text { coefficients } \\
h= & \text { height of node } i \\
\vec{J}^{B}= & \text { bottom neutron current } \\
\vec{J}^{T}= & \text { top neutron current } \\
\vec{\phi}_{i, g}^{B, H o m}= & \text { bottom homogeneous surface flux } \\
\vec{\phi}_{i, g}^{T, H o m}= & \text { top homogeneous surface flux. }
\end{aligned}
$$

The ZDFs are included in the PMAXS cross-section file for the top and bottom surfaces of a given material node. A separate cross-section file was created for each nodal region to accommodate the ZDFs and the 3D cross sections.

For interfaces with large gradients, such as the region between seed and blanket zones, the homogeneous flux can become negative, which leads to a negative discontinuity factor. This can result in negative fluxes within PARCS and numerical problems during the flux solution.
A scheme was developed to avoid this, based on modifying the diffusion coefficient such that the ZDF would be bounded within an acceptable range, while still preserving the net current on the node interface. However, the modification of the diffusion coefficient also affected the radial 2D calculation within TPEN, causing instabilities within the core calculation. To avoid this, limits were placed on the ZDFs. If the calculated value exceeded the specified range, then the quantity was changed to the closest bound.

In order to demonstrate that $3 \mathrm{D}$ cross sections with ZDFs can reproduce the same Monte Carlo solution, a single assembly benchmark problem was simulated. ${ }^{18}$ The axial configuration of the benchmark problem is shown in Fig. 11. The benchmark problem simulated a break-even type of RBWR design. The fissile Pu weight fraction in heavy metal (HM) was $15.7 \%$ and $20.1 \%$ for the upper and lower TRU zones, respectively. In the axial direction, in total 34 meshes were used: 5 in the lower blanket, 8 in the lower TRU, 8 in the internal blanket, 8 in the upper TRU, and 5 in the upper blanket, while using only a single mesh for each axial reflector. Reflective boundary conditions were applied to all sides of the assembly. The limit of ZDFs was set to the range of 0.85 to 1.15 , based on experiences to mitigate potential numerical issues in PARCS. Table IX shows the comparison of the single assembly benchmark results. When using only $3 \mathrm{D}$ cross sections, the PARCS solution was over 800 pcm different from the Serpent solution, which

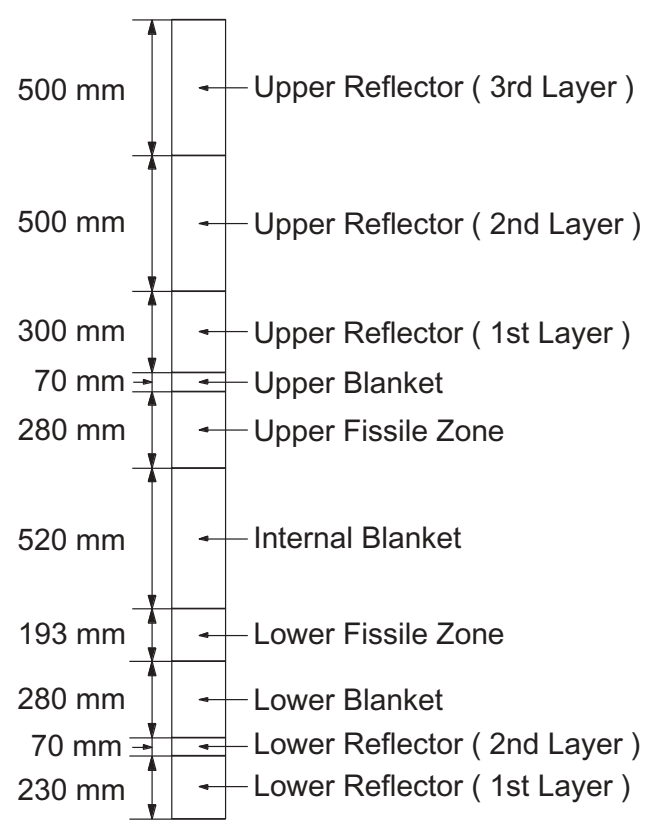

Fig. 11. Axial configuration of benchmark problem. 
TABLE IX

Eigenvalue Comparison for Single Assembly Benchmark

\begin{tabular}{|l|c|c|}
\hline \multicolumn{1}{|c|}{ Method } & kinf & $\begin{array}{c}\text { Difference From } \\
\text { Serpent (pcm) }\end{array}$ \\
\hline Serpent & 1.09601 & - \\
PARCS without ZDFs & 1.08772 & -829 \\
$\begin{array}{l}\text { PARCS with ZDFs } \\
\text { (no bound) } \\
\text { PARCS with ZDFs (bound) }\end{array}$ & 1.09601 & 0 \\
\hline
\end{tabular}

had a relative statistical error of $9.6 \mathrm{pcm}$. When ZDFs were introduced without bounding the range of ZDFs, PARCS reproduces the exact Serpent solution. When the range of ZDFs were bounded, there was a small difference of $44 \mathrm{pcm}$. This was an acceptable order of error for the purpose of comparing with the conventional analysis with $2 \mathrm{D}$ cross sections, which would have a difference larger than $800 \mathrm{pcm}$ in the case without ZDFs in Table IX.

\section{III.B.3. Thermal Hydraulics}

The PATHS code was developed to calculate a steady-state thermal-hydraulic solution for LWRs. PATHS utilizes a four-equation drift flux model with simplified equations and solution algorithms that considerably reduce the runtime. This enables one-to-one neutronics/thermal-hydraulic coupled calculations. The calculation scheme is similar to that used by Hitachi. The in-channel coolant flow rate, the two-phase flow pressure drop, and the axial void fraction distribution were calculated using the power distribution obtained by the core neutronic calculation, so that the pressure drops between fuel bundles were balanced. The user may choose from various void correlations in PATHS. For this study an EPRI void model ${ }^{17}$ was used.

\section{III.B.4. Core Modeling}

Since the core is one-third symmetric, 240 out of 720 fuel assemblies were modeled. The radial reflector region was represented by a ring of hexagonal nodes, whose total area was equal to 34 times the area of a single fuel lattice. The number of nodes/meshes for each axial zone is summarized in Table X. At the top of the active core, there exists a $300-\mathrm{mm}$-height bottom plenum region and the upper neutron absorber zone is replaced by a vacuum boundary condition. The lower neutron absorber is
TABLE $X$

Axial Node Segmentation in Michigan Method

\begin{tabular}{|l|c|c|}
\hline \multicolumn{1}{|c|}{ Zone } & Height $(\mathrm{mm})$ & $\begin{array}{c}\text { Number } \\
\text { of Mesh }\end{array}$ \\
\hline Upper neutron absorber & 500 & 1 \\
Bottom plenum & 300 & 1 \\
Upper blanket & 20 & 2 \\
Upper TRU & 224 & 8 \\
Internal blanket & 560 & 8 \\
Lower TRU & 221 & 8 \\
Lower neutron absorber & 70 & 1 \\
Lower reflector & 230 & 1 \\
\hline
\end{tabular}

modeled as a $30-\mathrm{mm}$-height layer and the lower reflector zone below it is replaced by a vacuum boundary condition.

An iterative algorithm has been developed to provide nested iterations to determine the equilibrium core configuration using the Serpent/PARCS/PATHS code system. The convergence criterion was set to $0.1 \mathrm{GWd}$ /tonne for the infinite norm of nodewise burnup at the end of cycle (EOC). It takes into consideration explicit treatment of control rod scheduling the same as in the Hitachi analysis, as shown in Fig. 10.

\section{CRITICAL POWER EVALUATION}

\section{IV.A. Hitachi Method}

The modified CISE correlation developed by Hitachi (Hitachi-CISE) is defined as follows:

$$
X_{c}=\frac{A \times L_{B}}{L_{B}+B} \times \frac{P_{h}}{P_{w}} \times R_{f}^{-1}
$$

where

$$
B=0.19875 \times\left(\frac{P_{c}}{P}-1\right)^{0.4} \times D_{e}^{1.4} \times G
$$

The factor $A$ is defined for the region of $1085 \leq G$ $\left(\mathrm{kg} / \mathrm{s} / \mathrm{m}^{2}\right)$ as follows:

$$
A=\frac{P / P_{c}}{(G / 1176)^{0.5}} \times F
$$

For the region of $406.8 \leq \mathrm{G}<1085\left(\mathrm{~kg} / \mathrm{s} / \mathrm{m}^{2}\right)$, 


$$
A=\frac{1-P / P_{c}}{(G / 1200)^{0.4}} \times F
$$

For the region of $G<406.8\left(\mathrm{~kg} / \mathrm{s} / \mathrm{m}^{2}\right)$,

$$
A=1-\frac{\left(1-A_{0}\right) \times G}{406.8}
$$

and

$$
A_{0}=\frac{1-P / P_{c}}{(406.8 / 1200)^{0.4}} \times F,
$$

where

$$
\begin{aligned}
X_{c} & =\text { critical quality } \\
R_{f} & =\text { maximum local peaking factor }(-) \\
G & =\text { mass flux } \\
P & =\text { pressure }(\mathrm{Pa}) \\
D_{e} & =\text { hydraulic diameter }(\mathrm{m}) \\
L_{B} & =\text { boiling length }(\mathrm{m}) \\
P_{h} & =\text { heated perimeter }(\mathrm{m}) \\
P_{w} & =\text { wetted perimeter }(\mathrm{m}) \\
P_{c} & =\text { critical pressure }(\mathrm{Pa}) \\
F & =1+0.1 \times\left(L_{B}-\max \left(1.5-\frac{\mathrm{P}}{1.379 \times 10^{7}}, 0.0\right)\right) .
\end{aligned}
$$

The Hitachi-CISE is based on critical heat flux data that were obtained by Bettis Atomic Power Laboratory (BAPL) with tight lattice bundles having 20 heater rods. The terms $A$ and $B$ were tuned to fit the experimental data. ${ }^{19}$ Unheated wall effect was implemented by the term of $P_{h} / P_{w}$. When boiling length is relatively long, the correlation without term $F$ tends to underestimate the critical quality; therefore, the $F$ factor was introduced in Eqs. (26), (27), and (29). Since there are few experimental data for low flow rate $\left(G<406.8 \mathrm{~kg} / \mathrm{s} / \mathrm{m}^{2}\right)$, the term $A$ was tuned so that the parameter $A$ became unity at zero flow rate, which can be derived theoretically.

\section{IV.B. MIT Method}

MIT further modified the CISE correlation (MIT-CISE) to fit a broader range of experimental data, including recent activities, than those used for developing Hitachi-CISE. The MIT-CISE is defined as follows:

$$
X_{c}=\frac{A \times L_{B}}{L_{B}+B} \times\left(\frac{P_{h}}{P_{w}}\right)^{0.83} \times R_{f}^{-1} .
$$

Notations are the same as those in the Hitachi-CISE. The functions $A$ and $B$ are defined as

$$
\begin{gathered}
A=\left\{\begin{array}{cc}
\left\{1.0+1.481 \times 10^{-4}\left(1-p_{c} / p\right)^{-3} 0.7 G\right\}^{-1} & G \leq G^{*} \\
\frac{1-p / p_{c}}{(G / 1000)^{0.33}} & G>G^{*}
\end{array},\right. \\
G^{*}=3375 \times\left(1-p / p_{c}\right),
\end{gathered}
$$

and

$$
B=0.199 \times\left(\frac{p_{c}}{p}-1\right)^{0.4} D_{e}^{1.2} G
$$

The form of the function $B$ is the same as that of Hitachi-CISE but a multiplier of hydraulic diameter $D_{e}$ is different. The function $\mathrm{A}$ is similar to that of Hitachi-CISE but the critical quality depends on pressure more strongly than in Hitachi-CISE under the low mass flow condition $\left(G \leq G^{*}\right)$. Experimental data used for MIT-CISE and evaluation results are listed in Table XI. JAEA-A, JAEA-B, JAEA-C, and JAEA-D are experiments with double-humped axial heating similar to the axial power distribution of a RBWR. The MIT-CISE showed no significant biasing on these experiments, except JAEA-A, for which MIT-CISE predicted critical powers smaller (more conservative) than the experimental value. From these results, MIT-CISE would be reliable for a RBWR within the current knowledge, though it needs to be confirmed by experiments simulating a RBWR configuration and condition precisely in the future.

\section{ANALYSIS RESULTS}

Figure 12 compares the axial void distribution between the Hitachi and Michigan methods. Figure 13 compares the axial power distributions and indicates large discrepancies in the upper blanket and at the top of the upper TRU region. As mentioned in Sec. III.A.2, the neutron energy spectrum in the $2 \mathrm{D}$ lattice calculation would differ the most from that in the practical core because of the incoming neutron current from the adjacent plenum region. Thus, the difference in group energy constants would become clear for the Michigan method, 


\section{TABLE XI}

Experimental Data Used for MIT-CISE

\begin{tabular}{|c|c|c|c|c|c|c|}
\hline Experiment & $\begin{array}{l}\text { Rod Diameter } \\
(\mathrm{mm})\end{array}$ & $\begin{array}{c}\text { Hydraulic } \\
\text { Diameter }(\mathrm{mm})\end{array}$ & $\begin{array}{l}\text { Pressure } \\
(\mathrm{MPa})\end{array}$ & $\begin{array}{c}\text { Number of } \\
\text { Rods/Heating }^{\text {a }}\end{array}$ & $\begin{array}{l}\text { Number of } \\
\text { Data Items }\end{array}$ & $\begin{array}{l}\text { Mean/Standard } \\
\text { Deviation }^{\mathrm{b}}\end{array}$ \\
\hline JAEA-A ${ }^{20}$ & 12.3 & 2.35 & 1.0 to 8.0 & $7 \mathrm{U}$ & 129 & $0.72 / 0.09$ \\
\hline $\mathrm{JAEA}^{2} \mathrm{~B}^{21}$ & 13 & 2.86 & 2.0 to 8.5 & $7 \mathrm{D}$ & 116 & $1.03 / 0.11$ \\
\hline JAEA-C ${ }^{22}$ & 13 & 4.42 & 2.0 to 8.5 & $37 \mathrm{D}$ & 117 & $1.02 / 0.08$ \\
\hline JAEA-D ${ }^{22}$ & 13 & 3.71 & 2.0 to 8.6 & $37 \mathrm{D}$ & 147 & $1.09 / 0.08$ \\
\hline Toshiba- $1^{23}$ & 10.8 & 4.85 & 7 & $7 \mathrm{C}$ & 6 & $1.22 / 0.10$ \\
\hline Toshiba- $2^{23}$ & 10.8 & 5.91 & 7 & $7 \mathrm{C}$ & 13 & $1.16 / 0.16$ \\
\hline Toshiba- $3^{23}$ & 10.8 & 7.03 & 7 & $7 \mathrm{C}$ & 6 & $0.91 / 0.02$ \\
\hline Toshiba- $4^{23}$ & 10.8 & 5.74 & 1.0 to 8.0 & $14 \mathrm{C}$ & 31 & $1.42 / 0.12$ \\
\hline
\end{tabular}

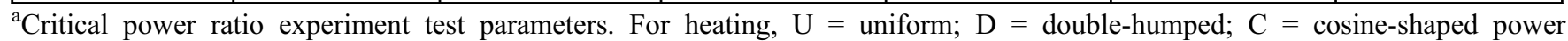
distribution.

${ }^{\mathrm{b}}$ Mean and standard deviation values for predicted/experimental critical power.

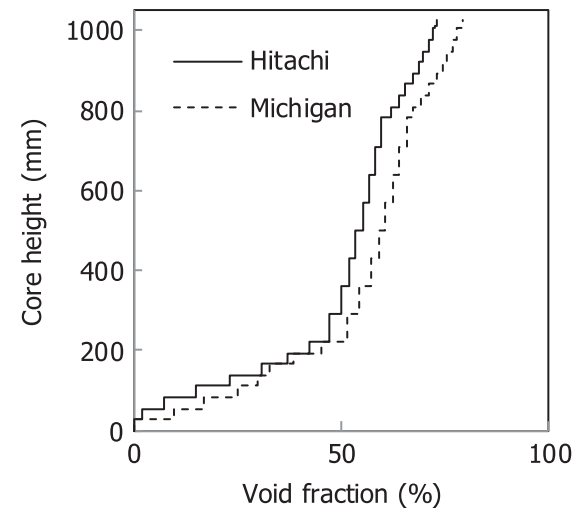

(a) BOC

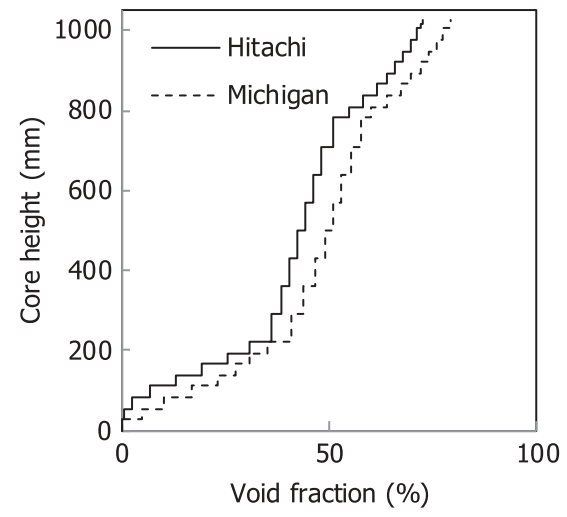

(b) EOC

Fig. 12. Axial void distribution.

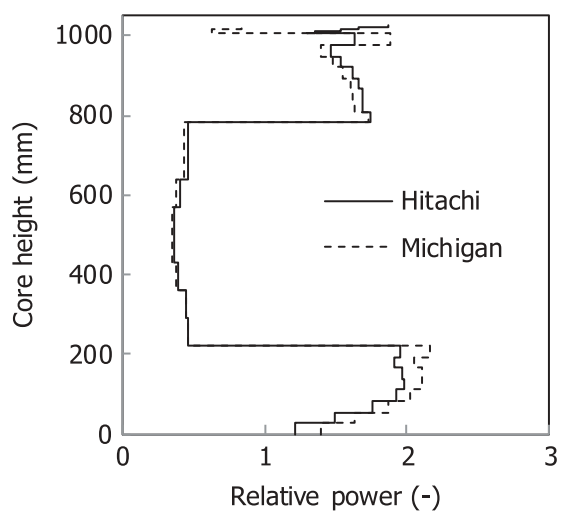

(a) BOC

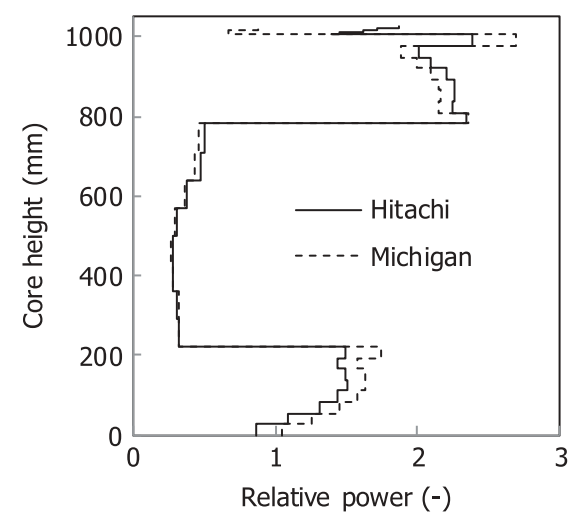

(b) EOC

Fig. 13. Axial power distribution.

which prepares the constants by a 3D single-bundle calculation, although in the Hitachi method the group energy constants are corrected by adjusting the historical void fraction. Despite the difference in the power of the upper blanket, there is little difference in the averaged isotopic composition of discharged fuels, as shown in Table XII. Although there is a relatively large difference in ${ }^{237} \mathrm{~Np}$, with its small composition it does not much affect overall 
TABLE XII

Comparison of Isotopic Vector (\%) of Discharged Fuel

\begin{tabular}{|l|r|r|}
\hline Isotope & Hitachi & Michigan \\
\hline${ }^{237} \mathrm{~Np}$ & 1.2 & 1.5 \\
${ }^{238} \mathrm{Pu}$ & 7.7 & 7.6 \\
${ }^{239} \mathrm{Pu}$ & 23.2 & 23.1 \\
${ }^{240} \mathrm{Pu}$ & 38.9 & 38.8 \\
${ }^{241} \mathrm{Pu}$ & 5.4 & 5.9 \\
${ }^{242} \mathrm{Pu}$ & 11.5 & 11.4 \\
${ }^{241} \mathrm{Am}$ & 5.4 & 4.9 \\
${ }^{242 \mathrm{~m}} \mathrm{Am}$ & 0.2 & 0.2 \\
${ }^{243} \mathrm{Am}$ & 3.0 & 2.9 \\
${ }^{244} \mathrm{Cm}$ & 2.4 & 2.6 \\
${ }^{245} \mathrm{Cm}$ & 0.7 & 0.7 \\
${ }^{246} \mathrm{Cm}$ & 0.4 & 0.4 \\
Total & 100.00 & 100.00 \\
\hline
\end{tabular}

core characteristics. Figure 14 shows comparison of radial power distributions. There are the noticeable differences in the beginning of cycle (BOC) radial shape, with the Michigan method predicting a lower power in the central region. It is suspected that this is because of differences in the control rod modeling, where the rods are deeply inserted into the center of the core at BOC.

Core analysis conditions and results are summarized in Table XIII. The core pressure drop was lower than that of the current ABWR design. In the thermalhydraulic design, the single-phase pressure drop at the lower tie plate was adjusted to make its ratio to the two-phase pressure drop adequate in terms of stability. The stability analysis with the coupled time domain approach was done for the previous design of the RBWR-TB2, and small but very slow decaying radial regional instabilities at $90 \%$ rated flow were reported. ${ }^{13}$ However, since the rated flow of the current design of the RBWR-TB2 was about 38\% higher than that of the previous design, a preliminary analysis showed its improved stability.

The minimum critical power ratio (MCPR) evaluated by the Michigan method with the MIT-CISE was smaller than that by the Hitachi method. This is because the MIT-CISE was fitted to experimental data other than BAPL data, which tend to be overestimated by the CISE-type correlation and were mainly used in

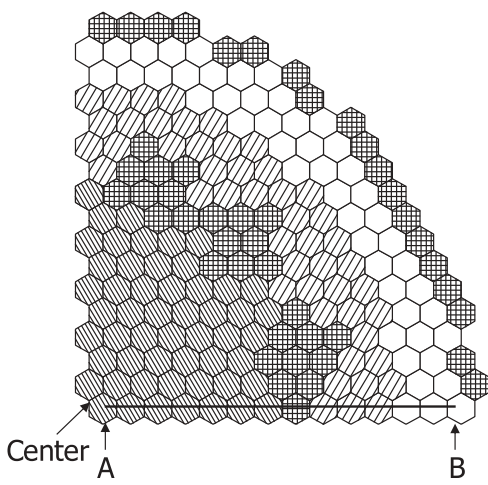

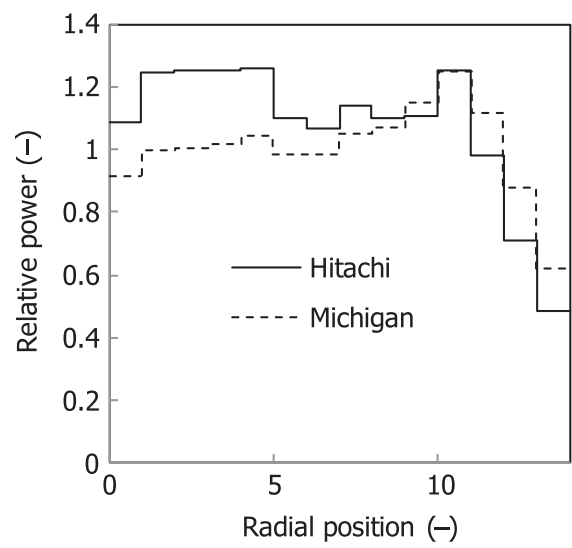

(a) BOC

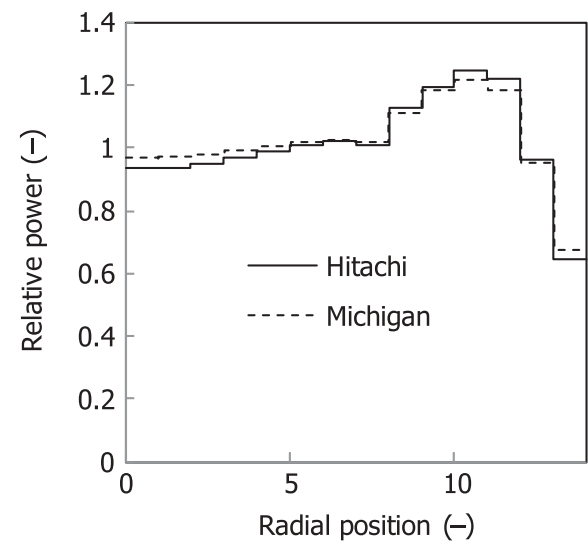

(b) EOC

Fig. 14. Radial power distribution. 
TABLE XIII

Core Analysis Conditions and Results

\begin{tabular}{|l|c|c|}
\hline \multicolumn{1}{|c|}{ Item } & Hitachi & Michigan/MIT \\
\hline $\begin{array}{l}\text { Nuclear data library } \\
\text { Coolant flow rate (kt/h) }\end{array}$ & JENDL-4.0 & ENDF/B-VII \\
$\begin{array}{l}\text { Average discharge burnup } \\
(\mathrm{GWd} / \text { tonne) }\end{array}$ & \multicolumn{2}{|c|}{63} \\
$\begin{array}{l}\text { Core-averaged void } \\
\text { fraction (\%) }\end{array}$ & 49 & 57 \\
$\begin{array}{l}\text { Pressure drop (MPa) } \\
\text { Minimum critical power } \\
\text { ratio }\end{array}$ & 0.11 & 0.05 \\
$\begin{array}{l}\text { Cold shutdown margin } \\
(\% \Delta \mathrm{k})\end{array}$ & 3.1 & 1.37 \\
$\begin{array}{l}\text { Void reactivity coefficient } \\
(\mathrm{pcm} / \% \text { void) }\end{array}$ & -23 & -8 \\
$\begin{array}{l}\text { Doppler coefficient } \\
(\mathrm{pcm} / \% \mathrm{~K})^{\mathrm{c}}\end{array}$ & -2.0 & -1.9 \\
\hline
\end{tabular}

${ }^{\mathrm{a}}$ End of cycle.

${ }^{\mathrm{b}}$ Active core region.

${ }^{\mathrm{c}}$ Most positive value through BOC/MOC/EOC.

constructing the Hitachi-CISE (Ref. 24). However, the safety analysis by MIT shows the peak cladding temperature (PCT) at the all-pump trip accident remains below the safety limit of $\sim 1480 \mathrm{~K}$, as described in Sec. VI. The cold shutdown margin was evaluated by Hitachi, which is a margin of k-effective to critical when a control rod with the largest worth is fully withdrawn from the core with all control rods inserted in cold condition, and it was larger than $3.0 \% \Delta \mathrm{k}$.

The Doppler and void reactivity coefficients were evaluated by changing core power by $\pm 10 \%$ and by changing coolant flow rate by $\pm 5 \%$ of nominal values, respectively. Table XIV shows a detailed comparison of the void reactivity coefficients. At all points in the burnup cycle, both the Hitachi and Michigan methods calculate the reactivity coefficients to be negative, although the absolute values of void reactivity coefficients in the Michigan method were slightly smaller than those in the Hitachi method.

The comparison of void reactivity coefficients between the Hitachi method and the Michigan method implies that a more sophisticated treatment of the axial heterogeneity tends to make void reactivity coefficients less negative. However, it is considered that its effect was as small as manageable by core design optimization, because the void reactivity coefficients are still negative by evaluation with the Michigan method.

\section{SAFETY ANALYSIS}

In the past studies, the all-pump trip and loss of coolant accidents were identified as the limiting accidents for RBWR-type design. ${ }^{3,25}$ This is because the relatively higher linear heating generation ratio, steam quality, and void fraction as well as smaller coolant volume in the RBWR-type core reduce its thermal capacity. Besides, the decrease in power to be brought by loss of coolant tends to become smaller due to less negative void reactivity coefficient. Thus, in this study, the behavior of the core against the all-pump trip accident was focused on and a coupled TRACE and PARCS analysis was conducted to evaluate the safety performance of the RBWR-TB2 core.

\section{VI.A. Methodology}

All RBWR plant systems, except for the core, are the same as the ABWR. A reference ABWR TRACE input deck was developed to model the vessel and plant systems of RBWR designs and was used for transient simulation. ${ }^{25}$ The core model in the ABWR deck consisted of 3 rings, 6 azimuthal sectors, and 16 separate channels of uniform radial peaking with no neutronic

\section{TABLE XIV}

Comparison of Reactivity Coefficients

\begin{tabular}{|c|l|c|c|c|c|}
\hline \multirow{2}{*}{} & \multicolumn{2}{|c|}{ Doppler Coefficient $(\mathrm{pcm} / \mathrm{K})$} & \multicolumn{2}{c|}{ Void Coefficient (pcm/\%void) } \\
\cline { 3 - 6 } & & $-10 \%$ Power & $+10 \%$ Power & $-5 \%$ Flow & $+5 \%$ Flow \\
\hline \multirow{2}{*}{ BOC } & Hitachi & -2.1 & -2.1 & -25.9 & -22.5 \\
& Michigan & -1.9 & -1.9 & -8.9 & -8.4 \\
MOC & Hitachi & -2.2 & -2.1 & -40.8 & -38.3 \\
& Michigan & -1.9 & -1.9 & -23.0 & -22.3 \\
& Hitachi & -2.0 & -2.1 & -35.4 & -34.1 \\
& Michigan & -2.0 & -1.9 & -13.8 & -14.5 \\
\hline
\end{tabular}


feedback modeling. The desired model for safety analysis required 720 separate channels, and this modification was made to the TRACE model. The ABWR deck lumps all steam separators into two separator components; however, all of the ABWR safety relief valves were explicitly modeled since they were critical in performing transient simulations. These valves were modeled with spring and relief set pressure in accordance to the GE ABWR design control document. ${ }^{26}$ The input model also contains explicit representation of all the four steam lines and ten internal reactor pumps in the ABWR design.

The ABWR model performance was assessed for selected transients and agreed well with the published results. ${ }^{25}$ In order to simulate the RBWR designs, the axial power profile, inlet temperature, pump flow rate, and core geometry of the 720 channels in TRACE were adjusted accordingly to the specification of each design. In order to quantify the MCPR, critical power correlations were added within TRACE source code. In order to calculate fuel temperature, the FRAPCON MOX thermal conductivity model ${ }^{27}$ was incorporated within TRACE to provide an accurate prediction of fuel temperature. The TRACE 3D burnup distribution in the core was taken from PATHS/PARCS simulation described in Sec. III.B.4. The same PARCS models that were used for the PATHS/PARCS simulations were coupled to the TRACE models.

\section{VI.B. Coupled TRACE/PARCS Steady-State Simulation}

The steady-state TRACE/PARCS simulations of the RBWR-TB2 were performed by restarting from the PATHS/PARCS converged solutions of the equilibrium cycle. A comparison of the two methods of simulation is shown in Table XV at BOC and EOC. As shown, there is an overall good agreement between the two simulation methods, especially on the core average moderator density, which corresponds to core average void fractions of $50 \%$ and $55 \%$ at $\mathrm{BOC}$ and EOC, respectively. The difference in the average fuel temperature is mainly due to the difference in the thermal conductivity models. As shown, even though the EOC peaking factors are milder, the average fuel temperatures predicted by TRACE increase due to higher burnups. The PATHS fuel thermal conductivity correlation is not dependent on burnup and was designed for $\mathrm{UO}_{2}$ fuel.

The core-averaged axial power peaking factors of both cores were found to be in good agreement. The comparison of PATHS and TRACE for prediction of RBWR-TB2 axial power distributions is shown in Fig. 15.

\section{VI.C. Analysis of All-Pump Trip Accident}

The sequence of events during the all-pump trip accident is listed in Table XVI and is consistent with the ABWR all-pump trip scenario. ${ }^{26}$

The PCT is the most important parameter to be assessed. The PCT also dictates the equivalent cladding reacted, if the cladding temperature exceeds at least $1000 \mathrm{~K}$. The typical safety limit imposed on Zircaloy cladding during core uncovery design basis accidents is the temperature limit of $\sim 1204^{\circ} \mathrm{C}\left(2200^{\circ} \mathrm{F}\right)$, to avoid excess oxidation.

During the accident the RPV pressure increased by $\sim 0.85 \mathrm{MPa}$, which is very close to a conventional ABWR transient response. ${ }^{26}$ The PCTs during the all-pump trip simulations performed are summarized in Table XVII. As shown, though the PCT was higher than that of a typical ABWR case, $\sim 800 \mathrm{~K}$ (Ref. 26), the calculated PCTs were well below the safety limit of $\sim 1480 \mathrm{~K}$ (Ref. 26).

\section{FUEL CYCLE CHARACTERISTICS}

The objective of this study is to compare the performance metrics of the RBWR-TB2 core with its SFR equivalent - the ABR designed by Argonne National Laboratory (ANL) (Ref. 28). For this comparison, the design

TABLE XV

PATHS/PARCS to TRACE/PARCS Simulations

\begin{tabular}{|l|c|c|c|c|}
\hline \multirow{2}{*}{ Item } & \multicolumn{2}{|c|}{ BOC } & \multicolumn{2}{|c}{ EOC } \\
\cline { 2 - 5 } & PATHS & TRACE & \multicolumn{2}{|c|}{ PATHS } \\
\hline Average fuel temperature $(\mathrm{K})$ & 850 & 986 & 847 & 1071 \\
Average fluid density $\left(\mathrm{g} / \mathrm{cm}^{3}\right)$ & 0.396 & 0.406 & 0.337 & 0.338 \\
Core $k_{\text {eff }}$ & 1.0289 & 1.0272 & 1.0213 & 1.0187 \\
Peak assembly factor & 1.266 & 1.294 & 1.283 \\
\hline
\end{tabular}




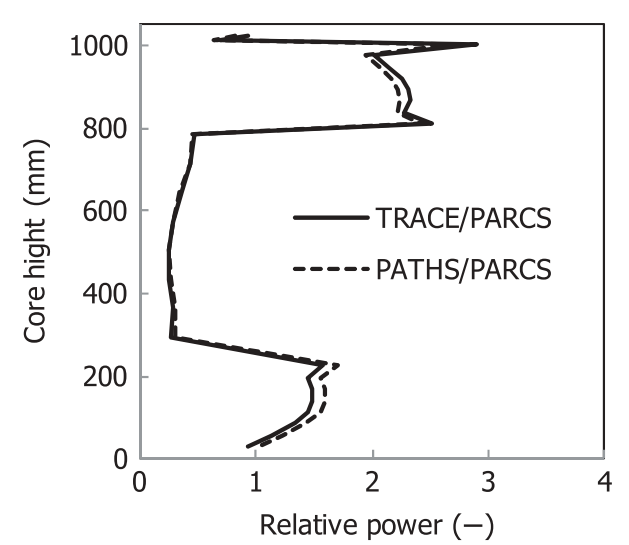

(a) $\mathrm{BOC}$

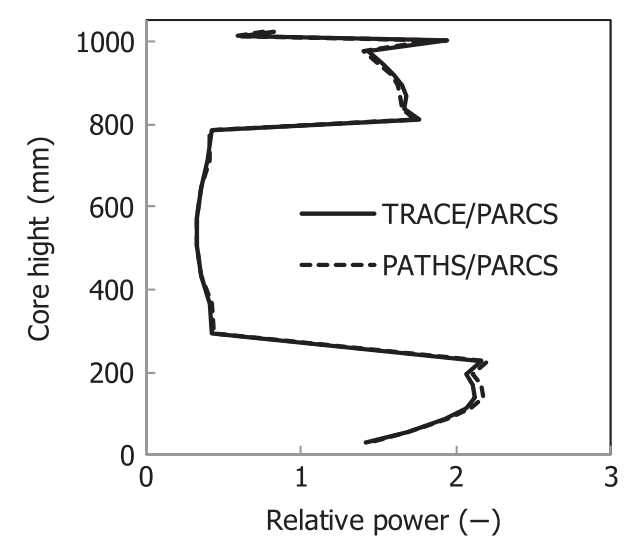

(b) EOC

Fig. 15. Comparison of axial power distribution by TRACE/PARCS and PATHS/PARCS.

TABLE XVI

All-Pump Trip Accident Sequence

\begin{tabular}{|l|l|}
\hline Time $(\mathrm{s})$ & \multicolumn{1}{|c|}{ Event } \\
\hline 0 & Trip of all reactor internal pumps initiated \\
1.22 & Reactor scram \\
1.85 & Feed water flow pump trip \\
1.97 & Turbine trip initiates bypass operation \\
20 & End of simulation \\
\hline
\end{tabular}

TABLE XVII

Evaluated PCT in All-Pump Trip Accident*

\begin{tabular}{|c|c|c|}
\hline BOC & EOC & Limit \\
\hline 977 & 892 & 1480 \\
\hline
\end{tabular}

*PCT in kelvins.

with conversion ratio $(\mathrm{CR})$ of 0.73 was chosen as the $\mathrm{ABR}$ to compare against, as it was recommended by ANL for early deployment. ${ }^{28}$ Nevertheless, the RBWR-TB2 is also compared against an equal $\mathrm{CR}$ of $0.5 \mathrm{ABR}$ even though this core features a steep burnup reactivity drop that limits its cycle to approximately 7 months.

\section{VII.A. Methodology}

\section{VII.A.1. Computation Method}

The performance of the RBWR-TB2 design used for this comparison was from the core analysis described in Sec. III.B. The ABR was designed by ANL using the
ANL-developed deterministic suit of fast reactor codes DIF3D/REBUS-3 supplemented by the MC2-3/TWODANT multigroup cross-section generating codes. ${ }^{28}$

The fresh fuel from the equilibrium cycle was depleted with ORIGEN2.2 (Ref. 29) up to the average discharge burnup to track the isotopic composition of the fuel; PARCS does not provide the isotopic composition explicitly. The one-group cross sections used in ORIGEN2.2 were generated by the Serpent ${ }^{14}$ neutronics calculations using a $3 \mathrm{D}$ single reflected assembly model (as used for group constant generation in Sec. III.B.2) to accurately account for the prevailing neutron spectra in the RBWR-TB2 core that features strong axial heterogeneity. A different cross-section library was used for each of the four axial fuel regions: lower seed, internal blanket, upper seed, and upper blanket, used to represent the core. The cross sections were taken at an assembly average composition of $30.0 \mathrm{GWd} /$ tonne and were assumed to be invariant with burnup. Each fuel region was burned with a constant flux inferred from the Serpent calculations and the fuel assembly average power. The discharge composition determined as described earlier was compared against Hitachi's discharge composition and found to be in reasonable agreement: The largest absolute difference was in ${ }^{239} \mathrm{Pu}$, which had a relative difference of less than $5 \%$. The largest relative difference was in ${ }^{242 \mathrm{~m}} \mathrm{Am}$, which went from $0.2 \%$ of TRUs to $0.3 \%$ of TRUs. The difference in the ${ }^{239} \mathrm{Pu}$ concentration is noticeable but it would not change the conclusions reported in the paper regarding the transmutation rate and comparison against the ABR. The waste characteristics of the discharged fuel were then calculated with ORIGEN2.2 accounting for 879 FPs and 128 actinides. 


\section{VII.A.2. Metrics for Comparison}

The comparison metrics are divided into three parts: core design parameters; core and fuel cycle performance characteristics; and waste characteristics. The core design parameters include the thermal/electrical power, fuel form, core dimensions, and intra-assembly design. The core and fuel cycle performance characteristics compared pertain to the equilibrium cycle and include fuel loading, specific power, power density, peak linear heat generation rate, average discharge burnup, reprocessing capacity, cycle length, burnup reactivity swing, and fuel composition at charge, discharge, and after 5 years of cooling. The fuel cycle costs of the RBWR and SFR designs were quantified accounting for both front-end and back-end activities. As the waste characteristics, inhalation and ingestion toxicities at long term (100 000 years) after fuel discharge were evaluated.

\section{VII.A.3. Assumptions}

The major assumptions used for this fuel cycle analysis are a thermal efficiency of $34.5 \%$ for the RBWRs and $40 \%$ for the ABR; 5 years of cooling of the discharged fuel before recycling; and $1.2 \%$ of the discharged $\mathrm{HM}$ is lost in the recycling and fabrication processes and ends up in the waste stream together with the FPs. Both ABR cores use metallic fuel, whereas the RBWR uses oxide fuel.
For the fuel cycle analysis, a two-stage system was assumed. Stage 1 consists of pressurized water reactors (PWRs), while stage 2 is composed of either RBWR or SFR. An equilibrium state is assumed such that the rate of TRU generation in stage-1 PWRs equals the TRU consumption rate by stage- 2 reactors. The RBWR-TB2 core was designed to recycle all $(98.8 \%)$ of the HM and to have a CR of about 0.5. PWRs rather than ABWRs were considered for this analysis because the recent Fuel Cycle Evaluation and Screening Campaign of the U.S. Department of Energy (DOE) (Ref. 30) picked PWRs to represent LWRs; the conclusions would be the same had ABWR been chosen to represent LWRs.

\section{VII.B. Basic Core Design Parameters}

Basic design parameters of both cores are compared in Table XVIII and their core-averaged neutron spectra are compared in Fig. 16. The reference ABR used for this comparison was designed by ANL and features a CR of 0.73 and a significantly harder neutron spectrum than the RBWR-TB2. Its design parameters are deduced from Ref. 28. For the fuel cycle analysis the performance of the RBWR-TB2 is also compared against that of a CR 0.5 ABR even though this core features unacceptably short cycles; the performance of the $\mathrm{CR}=0.5 \mathrm{ABR}$ core is taken from Ref. 31.

TABLE XVIII

Design Parameters of the RBWR-TB2 and ABR

\begin{tabular}{|l|l|l|}
\hline \multicolumn{1}{|c|}{ Parameter } & RBWR-TB2 & \multicolumn{1}{c|}{ ABR } \\
\hline Reactor power [MW(thermal)/MW(electric)] & $3926 / 1356$ & $1000 / 400$ \\
Fuel form & U-TRU oxide & U-10Zr-TRU metallic \\
Feed fuel & DU + LWR's TRU & DU + LWR's TRU \\
Coolant & Light water & Sodium \\
Cladding & Zircaloy & HT9 \\
Fuel lattice type & Hexagonal & Hexagonal \\
Control rod type & Y-type & Assembly type \\
Equivalent core height (mm) & 1025 & 813 \\
Upper/lower blankets (mm) & $200 /-$ & - \\
Internal blankets (mm) & 560 & - \\
Upper/lower driver (mm) & $224 / 221$ & $1.13 /-$ \\
Pin pitch-to-diameter ratio & 1.26 & 7.55 \\
Fuel pin outer diameter (mm) & 7.24 & 271 \\
Pins per assembly & 397 & 75.0 \\
Fuel smeared density (\%) & 89.9 & 180 \\
Number of fuel assemblies & 720 & \\
\hline
\end{tabular}




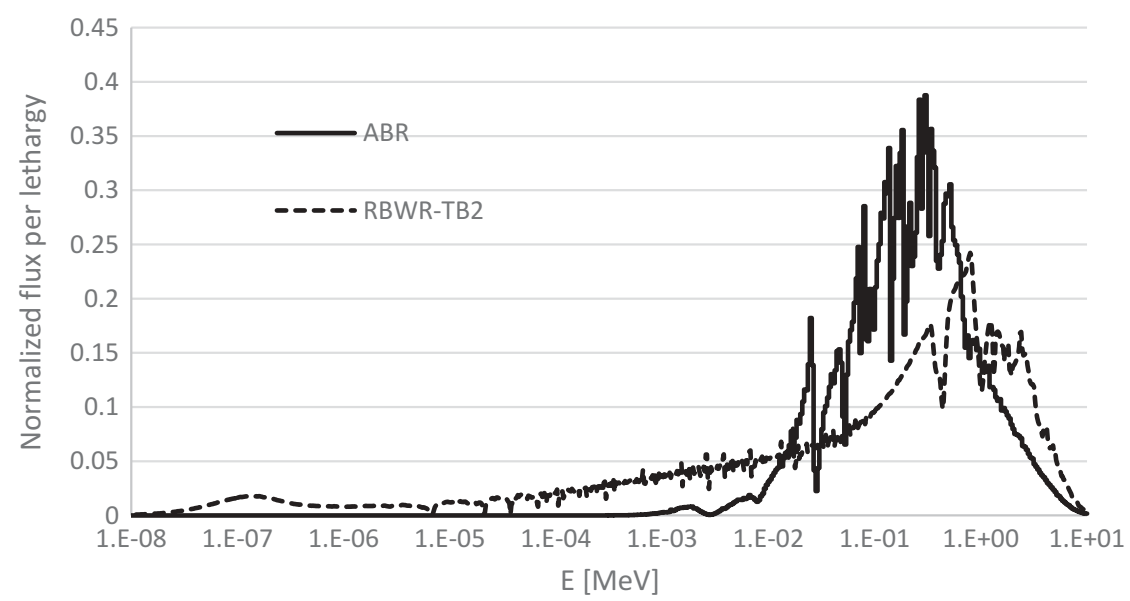

Fig. 16. Core-averaged neutron spectra of RBWR-TB2 and reference ABR.

\section{VII.C. Fuel Cycle Characteristics}

Figure 17 shows a schematic view of the RBWRTB2 and ABR fuel cycles considered. These cores are designed to incinerate TRUs recovered from LWR used nuclear fuel (UNF) and operate on a closed fuel cycle. The first stage consists of a typical PWR fed by $4.5 \%{ }^{235} \mathrm{U}$-enriched UOX fuel that is burned up to $50 \mathrm{MWd} / \mathrm{kg}$ followed by 10 years of cooling. The TRUs recovered from the PWR - the composition of which is given in Table XIX - were used to feed the second-stage cores, either the RBWR-TB2 or the ABR, after mixing with depleted uranium. The fuel mass loaded in stage- 1 reactors per unit of electricity generation was obtained from

$$
M^{i}=\frac{P_{t h}^{i}}{B U(i) \times P_{e l}^{i}} \cdot \frac{365 \mathrm{~d}}{1 \mathrm{yr}}
$$

where

$M^{i}=$ the fuel mass charged per $\mathrm{GW} \cdot \mathrm{yr}$ (electric) to stage $i$; it is equal to mass of fuel sent per $\mathrm{GW} \cdot \mathrm{yr}$ (electric) to the reprocessing facility

$P_{t h}^{i}$ and $P_{e l}^{i}=$ the thermal and electrical power for stage $i$

$$
B U(i)=\text { the discharge burnup for stage } i .
$$

At the equilibrium state, the TRU mass discharge rate from stage 1 equals the TRU incineration rate in stage 2. That is,

$$
F_{e l}^{1} \times T R U_{P}^{1}=F_{e l}^{2} \times T R U_{D}^{2}
$$

where

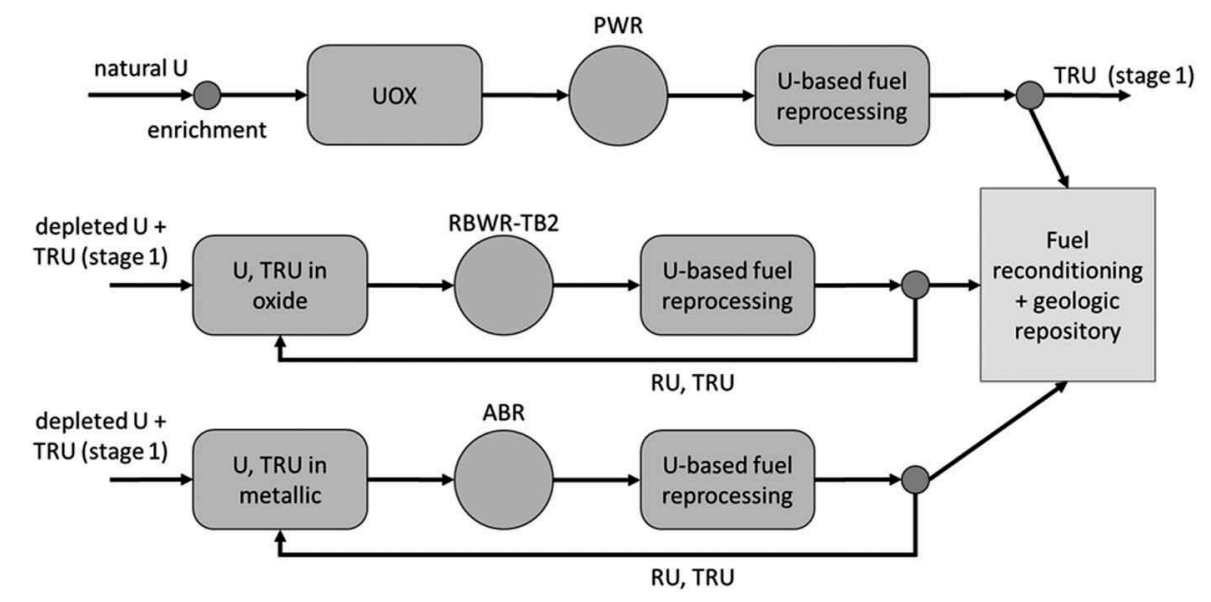

Fig. 17. Schematic view of the RBWR-TB2 and ABR fuel cycles. 


\section{TABLE XIX}

Composition of TRUs Extracted from LWR's UNF Discharge at $50 \mathrm{MWd} / \mathrm{kg}$ and Cooled for 10 Years*

\begin{tabular}{|l|c|}
\hline Isotope & Weight Percent \\
\hline${ }^{237} \mathrm{~Np}$ & $4.7 \%$ \\
${ }^{238} \mathrm{Pu}$ & $2.2 \%$ \\
${ }^{239} \mathrm{Pu}$ & $47.3 \%$ \\
${ }^{240} \mathrm{Pu}$ & $22.8 \%$ \\
${ }^{241} \mathrm{Pu}$ & $8.4 \%$ \\
${ }^{242} \mathrm{Pu}$ & $6.8 \%$ \\
${ }^{241} \mathrm{Am}$ & $5.6 \%$ \\
${ }^{243} \mathrm{Am}$ & $1.6 \%$ \\
${ }^{244} \mathrm{Cm}$ & $0.5 \%$ \\
\hline
\end{tabular}

*Reference 28.

$F_{e l}^{i}=$ fraction of the system electricity generated from stage $i$ reactors such that

$$
F_{e l}^{1}+F_{e l}^{2}=1
$$

and

$$
\frac{F_{e l}^{1}}{1-F_{e l}^{1}}=\frac{T R U_{D}^{2}}{T R U_{P}^{1}}
$$

and where

$T R U_{P}^{1}=$ the net amount of TRUs produced in stage- 1 reactors (not including TRU losses) per unit of electricity they generate $[\mathrm{kg} / \mathrm{GW} \cdot \mathrm{yr}(\mathrm{elec}-$ tric)], and

$T R U_{D}^{2}=$ The amount of TRUs incinerated in stage- 2 reactors per unit of electricity they generate $[\mathrm{kg} / \mathrm{GW} \cdot \mathrm{yr}($ electric $)]$.

The typical $T R U_{P}^{1}$ for a PWR with discharge burnup of $50 \mathrm{MWd} / \mathrm{kg}$ is $251.0 \mathrm{~kg} / \mathrm{GW} \cdot \mathrm{yr}$ (electric). The support ratio $S$ is defined as the ratio of electricity generated by stage-1 reactors to the electricity generated by the capacity of stage- 2 reactors required for transmuting stage- 1 generated TRUs at the rate of its generation. That is,

$$
S=\frac{F_{e l}^{1}}{F_{e l}^{2}}=\frac{T R U_{D}^{2}}{T R U_{P}^{1}}
$$

If a reactor can be designed with a small $\mathrm{CR}$, then the support ratio will be increased, which will reduce the fractional cost of the transmuting reactors in the energy system.
Table XX compares the performance characteristics of the RBWR-TB2 with those of two ABR cores: the reference $\mathrm{CR}=0.73 \mathrm{ABR}$ that is designed for near-term implementation, and an ABR that has the same CR of 0.5 (Ref. 31) as the RBWR-TB2. The RBWR-TB2 core has a smaller burnup and therefore features higher fuel reprocessing and fabrication capacity than the ABRs. The RBWR-TB2 core has a CR of about 0.5 , which leads to a support ratio of about 2; about one-third of the total system power is generated from stage 2 . In other words, on a per electrical power basis, the RBWR-TB2 is capable of incinerating TRUs at twice the rate that they are produced in typical PWRs. Per unit of generated electricity, the TRU transmutation of the $\mathrm{CR}=0.73 \mathrm{ABR}$ is significantly lower than that of the RBWR and its support ratio is only about 1 , while the TRU transmutation of the $\mathrm{CR}=0.5 \mathrm{ABR}$ is somewhat smaller than that of the RBWR-TB2 primarily because it has a higher energy conversion efficiency. For this reason, the support ratio of the $\mathrm{CR}=0.5 \mathrm{ABR}$ is somewhat less than 2 .

The discharged fuel composition after 5 years of cooling is shown in Table XXI; it is used for later fuel cycle analysis. In the RBWR-TB2 system that features a softer spectrum, a larger fraction of the discharged plutonium is composed of nonfissile isotopes.

\section{VII.D. Waste Characteristics}

Radioactivity of the UNF and high-level waste (HLW) was quantified at long term (100 000 years) after the fuel is discharged from the cores. Of the recycled HM, $1.2 \%$ is assumed to get into the HLW stream. ORIGEN 2.2 is used for the decay calculation. The inhalation toxicity and ingestion toxicity of UNF + HLW are calculated by considering different types of radiation on different parts of the human body. The values of the activity were weighted by the inhalation and ingestion conversion factor (207 FPs and 91 actinides in Ref. 32).

Figure 18 compares the inhalation and ingestion toxicity at 100000 years. The fuel discharged from the PWR has much lower $\mathrm{Pu}$ and minor actinide (MA) contents than the fuel discharged from the second stage. As a result, the FPs, $\mathrm{Pu}$, and MA in the fuel discharged from the first stage contribute very little of the total inhalation toxicity of the two-stage systems. Since the reprocessing capacity of the RBWR-TB2 is higher than that for the ABR system and a larger amount of HM gets into the HLW stream, the ABR features less inhalation toxicity.

Regarding the ingestion toxicity at 100000 years, the decay daughters from ${ }^{238} \mathrm{Pu}\left({ }^{210} \mathrm{Po}\right.$ and $\left.{ }^{210} \mathrm{~Pb}\right)$ contribute 
TABLE XX

Performance Characteristics of the RBWR-TB2 and ABR Systems

\begin{tabular}{|c|c|c|c|}
\hline Parameter & RBWR-TB2 & ABR (Ref. 28) & ABR (Ref. 31) \\
\hline $\begin{array}{l}\text { Conversion ratio } \\
\text { Capacity factor }(\%) \\
\text { Average discharge burnup }(\mathrm{GWd} / \text { tonne }) \\
\text { Specific power }(\mathrm{MWth} / \mathrm{t}) \\
\text { Power density }\left(\mathrm{W} / \mathrm{cm}^{3}\right) \\
\text { Peak LHGR }(\mathrm{W} / \mathrm{cm})^{\mathrm{a}} \\
\text { Number of batches } \\
\text { Fuel inventory in core }(\mathrm{t}) \\
\text { Fuel residence time }(\mathrm{EFPD})^{\mathrm{b}} \\
\text { Cycle length per batch }(\mathrm{EFPD})^{\mathrm{b}} \\
\text { TRU transmutation rate }[\mathrm{kg} / \mathrm{GW} \cdot \mathrm{yr}(\mathrm{electric})] \\
\text { TRU transmutation rate }[\mathrm{kg} / \mathrm{GW} \cdot \mathrm{yr}(\mathrm{thermal})] \\
\text { TRU transmutation efficiency }(\%) \\
\text { Power fraction }(\%) \\
\text { Stage } 1 \text { (PWR) } \\
\text { Stage } 2 \\
\text { Support ratio } \\
\text { Reprocessing capacity }[\mathrm{kg} / \mathrm{GW} \cdot \mathrm{yr}(\text { electric })] \\
\text { SNF from first stage }{ }^{\mathrm{c}} \\
\text { SNF from second stage } \\
\text { Pu from second stage } \\
\text { TRUs from second stage }\end{array}$ & $\begin{array}{c}0.5 \\
90 \\
65.0 \\
47.9 \\
96.7 \\
472 \\
4 \\
81.9 \\
1355.6 \\
338.9 \\
533.6 \\
185 \\
49 \\
\\
68.0 \\
32.0 \\
2.13 \\
14893.8 \\
5201.2 \\
1230.4 \\
1433.0\end{array}$ & $\begin{array}{c}0.73 \\
85 \\
93.0 \\
75.8 \\
163.0 \\
372 \\
4 \\
13.2 \\
1228 \\
307 \\
267.9 \\
107 \\
30 \\
\\
51.7 \\
48.3 \\
1.07 \\
11328.2 \\
4736.5 \\
832.8 \\
917.7\end{array}$ & $\begin{array}{c}0.5 \\
85 \\
131.9 \\
105.3 \\
130.4 \\
327 \\
6 \\
9.5 \\
1253 \\
221 \\
435 \\
174 \\
45 \\
\\
63.4 \\
36.6 \\
1.73 \\
13435.8 \\
2673.8 \\
759.5 \\
836.9\end{array}$ \\
\hline $\begin{array}{l}\text { Charge mass fraction }(\%) \\
{ }_{238} \mathrm{U} \\
\text { TRUs } \\
\text { Discharge mass fraction }(\%) \\
{ }^{238} \mathrm{U} \\
{ }_{\text {TRUs }} \\
\text { FPs } \\
\text { Fuel mass at time of recycle }(\%) \\
{ }_{238} \mathrm{U} \\
\text { TRUs } \\
\text { FPs }\end{array}$ & $\begin{array}{r}69.2 \\
30.8 \\
65.7 \\
27.6 \\
6.7 \\
\\
65.8 \\
27.6 \\
6.7\end{array}$ & $\begin{array}{r}77.9 \\
22.1 \\
\\
71.4 \\
19.4 \\
9.2 \\
\\
71.4 \\
19.4 \\
9.2\end{array}$ & $\begin{array}{l}66.7 \\
33.3 \\
\\
59.6 \\
27.6 \\
12.8 \\
\\
59.7 \\
27.5 \\
12.8\end{array}$ \\
\hline
\end{tabular}

${ }^{\mathrm{a}} \mathrm{LHGR}=$ linear heat generation rate.

${ }^{\mathrm{b}} \mathrm{EFPD}=$ effective full-power days.

${ }^{\mathrm{c}} \mathrm{SNF}=$ spent nuclear fuel.

significantly more ingestion toxicity for the RBWR-TB2 system than for the ABR.

\section{VII.E. Fuel Cycle Cost Aspects}

The economics of nuclear power plants are usually measured by the levelized electricity cost, which is composed of the capital cost, operation-and-maintenance (O\&M) cost, and fuel cycle cost. Due to the large uncertainty in the SFR capital and O\&M costs, this analysis focuses on the fuel cycle cost, accounting for both frontend and back-end cost components. Due to the high fissile contents in the discharged fuel, aqueous reprocessing and low enriched UOX fabrication technology developed for conventional PWR fuel may not be applicable for the RBWR. This study assumes that the RBWR discharged fuel undergoes electrochemical reprocessing and remote fuel fabrication, as planned for the SFRs based on the experience gained in the EBR-II project in the United States. The assumed costs of major activities in the fuel cycle were based on references and are summarized in Table XXII.

The fuel cycle cost of the PWR-RBWR system is $0.910 \AA / \mathrm{kW} \cdot \mathrm{h}($ electric), while the fuel cycle cost of the 
TABLE XXI

Discharged Fuel Composition (\%) of the RBWR-TB2 and ABR After 5 Years of Cooling

\begin{tabular}{|l|r|r|}
\hline Nuclide & RBWR-TB2 & ABR \\
\hline${ }^{234} \mathrm{U}$ & 0.14 & 0.04 \\
${ }^{235} \mathrm{U}$ & 0.09 & 0.09 \\
${ }^{236} \mathrm{U}$ & 0.04 & 0.02 \\
${ }^{238} \mathrm{U}$ & 70.19 & 78.51 \\
${ }^{237} \mathrm{~Np}$ & 0.40 & 0.28 \\
${ }^{238} \mathrm{Pu}$ & 2.17 & 0.58 \\
${ }^{239} \mathrm{Pu}$ & 6.59 & 10.15 \\
${ }^{240} \mathrm{Pu}$ & 11.60 & 6.44 \\
${ }^{241} \mathrm{Pu}$ & 1.56 & 0.70 \\
${ }^{242} \mathrm{Pu}$ & 3.45 & 1.48 \\
${ }^{241} \mathrm{Am}$ & 1.72 & 0.76 \\
${ }^{242 \mathrm{~m}} \mathrm{Am}$ & 0.10 & 0.05 \\
${ }^{243} \mathrm{Am}$ & 0.91 & 0.48 \\
${ }^{244} \mathrm{Cm}$ & 0.68 & 0.28 \\
${ }^{245} \mathrm{Cm}$ & 0.22 & 0.07 \\
${ }^{246} \mathrm{Cm}$ & 0.12 & 0.04 \\
\hline
\end{tabular}

PWR-ABR system is $0.762 \phi / \mathrm{kW} \cdot \mathrm{h}$ (electric). The smaller reprocessing capacity of the $A B R$, due to its substantially higher average discharge burnup, reduces the fuel cycle cost of the PWR-ABR system compared to that of the PWR-RBWR systems. The larger fraction of power from Tier 1 of the PWR-RBWR system partially compensates the effect of lower burnup of the RBWRs.

Even though the fuel cycle cost of the PWR-ABR system is lower than that of the PWR-RBWR system, the levelized cost of electricity of the PWR-RBWR system is likely to be lower, as past economic analyses concluded that the uncertainty in the capital cost of SFRs is larger than that of LWRs.
TABLE XXII

Cost of Major Fuel Cycle Activities*

\begin{tabular}{|l|r|}
\hline \multicolumn{1}{|c|}{ Fuel Cycle Activity } & Cost \\
\hline Natural uranium mining and milling & 60 \\
$\quad$ \$/kg U) & 100 \\
Thorium mining and milling (\$/kg Th) & 10 \\
Conversion processes (\$/kg U or Th) & 105 \\
Enrichment (\$/SWU $)$ & 240 \\
LWR UO ${ }_{2}$ fuel fabrication (\$/kg U) & 1000 \\
\hline UREX aqueous separation (\$/kg HM) & 5000 \\
Reprocessing-electrochemical and remote & \\
fuel fabrication (\$/kg HM) & 1100 \\
\hline SNF conditioning/packaging/disposal & 93 \\
(\$/kg HM) & 2000 \\
RU conditioning (\$/kg HM) & 10000 \\
Aqueous HLW conditioning/storage/ & \\
packaging (FPs + Ln) (\$/kg FPs) & \\
Geologic repository (HLW FPs + Ln + Tc) & \\
(\$/kg FPs) &
\end{tabular}

*Reference 33.

${ }^{\mathrm{a}} \mathrm{SWU}=$ separative work unit.

\section{CONCLUSIONS}

This paper discussed the research performed on the core design and analysis of the RBWR-TB2, which is a BWR capable of burning TRUs. The RBWR-TB2 core is characterized by the use of hexagonal tight pitch lattice fuel assemblies, in order to achieve the hard neutron spectra suitable for fissioning fertile TRUs and the axially heterogeneous core configuration to maintain the void reactivity coefficient negative. Two separate core analyses were

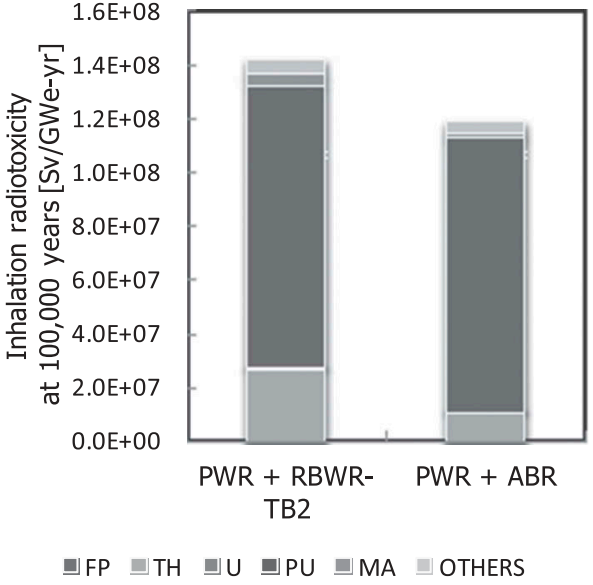

(a) Inhalation toxicity

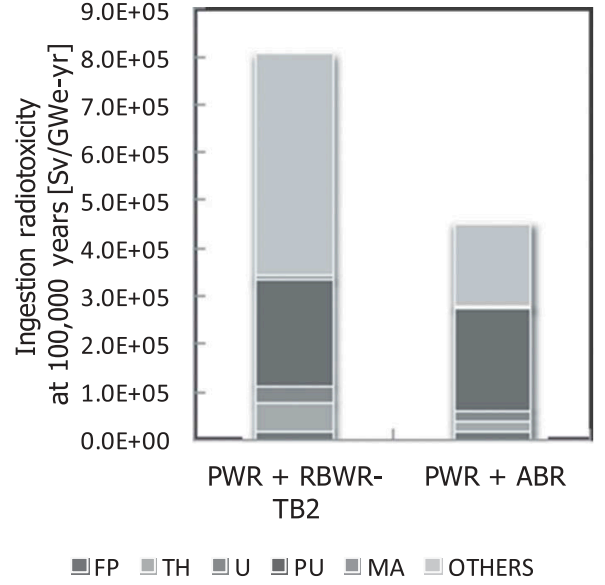

(b) Ingestion toxicity

Fig. 18. Toxicities of the waste stream from RBWR-TB2 and ABR at 100000 years. 
performed by Hitachi and Michigan. The Hitachi core analysis used the conventional 2D group energy constants combined with the historical void fraction correction method. In this analysis, the historical void fraction used as an index for interpolating group energy constants for the upper blanket region adjacent to the plenum region was corrected to reproduce a neutron spectrum in the practical core softer than that in the infinite $2 \mathrm{D}$ lattice calculation. The Michigan method was based on group constants generated using a 3D Monte Carlo model of each fuel assembly, as well as ZDFs to account for the large axial change of both the neutron flux level and energy spectrum between the depleted uranium blanket region and the TRU region.

CISE-type correlations were used for the critical power evaluation in the core analyses. The correlation based on the BAPL data was used in the Hitachi analysis. The correlation based on the best estimate for the broader range of experimental data by MIT was used in the core analysis of Michigan.

Core characteristics in the equilibrium cycle were evaluated by the two methodologies. Negative void reactivity coefficients were found in both analyses for all points in the burnup cycle. The minimum critical power ratio evaluated by MIT was smaller than that evaluated by Hitachi, but the safety analysis by MIT showed that the PCT remains below the safety limit for the limiting all-pump trip accident.

Detailed fuel cycle analysis by University of California, Berkeley, showed that per electrical power generated, the RBWR-TB2 is capable of incinerating TRUs at twice the rate that they are produced in typical PWRs. Compared with the SFR TRU burner, ABR, the larger reprocessing capacity of the RBWR, due to its substantially lower average discharge burnup, leads to a larger amount of HM getting into the HLW stream. This results in higher long-term toxicity of HLW from the RBWR-TB2 system than that from the ABR system. Even though the fuel cycle cost of the ABR system is lower than that of the RBWR-TB2 system, the capital cost uncertainty of LWRs is lower than that of SFRs and the levelized cost of electricity of the RBWR-TB2 system may be lower.

The RBWR-TB2 core characteristics discussed in this paper focused on improved methods to account for the exceptionally large axial heterogeneity of this core and for critical power prediction. Investigation of other RBWR-TB2-related issues, such as the effect of uncertainties in nuclear data, fuel cladding integrity, and so on, is in progress.

\section{ORCID}

T. Hino (1) http://orcid.org/0000-0003-0577-4155

\section{References}

1. R. TAKEDA et al., "BWRs for Long-Term Energy Supply and for Fissioning Almost All Transuraniums," Proc. GLOBAL 2007, Boise, Idaho, September 9-13, 2007.

2. R. TAKEDA et al., "RBWRs for Fissioning Almost All Uranium and Transuraniums," Trans. Am. Nucl. Soc., 107, 853 (2012).

3. R. TAKEDA et al., "A Conceptual Core Design of Plutonium Generation Boiling Water Reactor," Proc. 1988 Int. Reactor Phys. Conf., Vol. 3, p. 119 (1988).

4. T. DOWNAR et al., "Technical Evaluation of the Hitachi Resource-Renewable BWR (RBWR) Design Concept," EPRI Technical Report 1025086, Electric Power Research Institute (2012).

5. W. S. YANG et al., "Performance Characteristics of Metal and Oxide Fuel Cores for a $1000 \mathrm{MWt}$ Advanced Burner Reactor," Proc. ARWIF08, Fukui, Japan, February 2008.

6. S. TAKAHASHI et al., "Development of RBWR (Resource-Renewable BWR) for Recycling and Transmutation of Transuranium Elements (2)Development of Reactor Internal," Proc. ICAPP 2015, Nice, France, May 3-6, 2015.

7. Y. KOIDE and S. KOYAMA, "Development of RBWR (Resource-Renewable BWR) for Recycling and Transmutation of Transuranium Elements (3)-Vibration Analysis of Fuel Assembly," Proc. ICAPP 2015, Nice, France, May 3-6, 2015.

8. S. TAKAHASHI et al., "Development of RBWR (Resource-Renewable BWR) Fuel Assembly Components for Recycling and Transmutation of Transuranium Elements," Proc. ICAPP 2016, San Francisco, California, April 17-20, 2016.

9. K. OKADA et al., "Development of RBWR for LongLived Transuranium Elements Burner (14) Feasibility Study of a Nuclear Instrumentation System for RBWR," Preprints, 2016 Fall Meeting of the Atomic Energy Society of Japan, Kurume, Japan, September 7-9, 2016 (in Japanese).

10. Y. MORIMOTO et al., "Neutronic Analysis Code for Fuel Assembly Using a Vectorized Monte Carlo Method," Nucl. Sci. Eng., 103, 351 (1989); https://doi.org/10.13182/ NSE89-A23688.

11. T. B. FOWLER et al., "Nuclear Reactor Core Analysis Code CITATION," ORNL-TM-2496, Oak Ridge National Laboratory, Supplement 1 (Oct. 1971), Supplement 2 (Mar. 1972), Supplement 3 (July 1972).

12. R. T. LAHEY JR. and F. J. MOODY, The ThermalHydraulics of a Boiling Water Nuclear Reactor, American Nuclear Society, La Grange Park, Illinois (1977). 
13. T. DOWNAR et al., "Transient Safety Analysis of Fast Spectrum TRU Burning LWRS With Internal Blankets," NEUP Final Report, Project No. 11-3152 (2015).

14. J. LEPPÄNEN, "PSG2/Serpent-A Continuous-Energy Monte Carlo Reactor Physics Burnup Calculation Code" (2009); http://montecarlo.vtt.fi (current as of Jan. 23, 2017).

15. Y. XU and T. DOWNAR, "GenPMAXS-V5, Code for Generating the PARCS Cross Section Interface File PMAXS," University of Michigan (2009).

16. T. DOWNAR et al., "PARCS, U.S. NRC Core Neutronics Simulator," University of Michigan (2009).

17. A. WYSOCKI et al., "PATHS: PARCS Advanced Thermal Hydraulic Solver," University of Michigan (2012).

18. A. HALL, "Homogenization Methods for Full Core Solution of the Pn Transport Equations with 3-D Cross Sections," PhD Thesis, University of Michigan (2017).

19. B. W. LETOURNEAU et al., "Critical Heat Flux and Pressure Drop Tests with Parallel Upflow of High Pressure Water in Bundles of Twenty 0.25- and 0.28-Inch Diameter Rods," WAPD-TM-1013 (1975).

20. M. KURETA and H. AKIMOTO, "Critical Power Correlation for Axially Uniformly Heated Tight-Lattice Bundles," Nucl. Technol., 143, 1, 89 (2003); https://doi. org/10.13182/NT143-89.

21. W. LIU et al., "Critical Power in 7-Rod Tight Lattice Bundle,” JSME Int. J. Ser. B, 47, 2, 299 (2005); https://doi. org/10.1299/jsmeb.47.299.

22. W. LIU et al., "An Improved Critical Power Correlation for Tight-Lattice Rod Bundles," J. Nucl. Sci. Technol., 44, 4, 558 (2007); https://doi.org/10.1080/18811248.2007.9711845.

23. T. YAMAMOTO et al., "Thermal Hydraulic Performance of Tight Lattice Bundle,” JSME Int. J., 49, 2, 334 (2006); https://doi.org/10.1299/jsmeb.49.334.

24. K. SHIRVAN et al., "Best Estimate Void Fraction and Critical Power Correlations for Tight Lattice BWR
Bundles," Proc. ICAPP 2013, Jeju Island, Korea, April 14-18, 2013.

25. K. SHIRVAN et al., "Stability and Safety Analysis of Tight Lattice Breeding LWR," Proc. ICAPP 2014, Charlotte, North Carolina, April 6-9, 2014.

26. "ABWR Design Control Document/Tier 2," General Electric (2007); https://www.nrc.gov/reactors/new-reac tors/design-cert/abwr.html (current as of Jan. 23, 2017).

27. K. J. GEELHOOD et al., "FRAPCON-3.4: A Computer Code for the Calculation of Steady-State ThermalMechanical Behavior of Oxide Fuel Rods for High Burnup," NUREG/CR-7022, Vol. 1, Pacific Northwest National Laboratory (2011).

28. T. K. KIM et al., "Core Design Studies for a 1000 MWth Advanced Burner Reactor," Ann. Nucl. Energy, 36, 3, 331 (2009); https://doi.org/10.1016/j.anucene.2008.12.021.

29. A. G. CROFF, ORIGEN2-A Revised and Updated Version of the Oak Ridge Isotope Generation and Depletion Code, ORNL-5621, Oak Ridge National Laboratory (1980).

30. R. WIGELAND et al., "Nuclear Fuel Cycle Evaluation and Screening-Final Report," INL/EXT-14-31465, Idaho National Laboratory (2014).

31. E. A. HOFFMAN et al., "Preliminary Core Design Studies for the Advanced Burner Reactor over a Wide Range of Conversion Ratios," ANL-AFCI-177, Argonne National Laboratory (2006).

32. K. ECKERMAN et al., "Compendium of Dose Coefficients Based on ICRP Publication 60," ICRP Publication 119, Ann. ICRP 41(Suppl.), International Commission on Radiological Protection (2012).

33. D. E. SHROPSHIRE et al., "Advanced Fuel Cycle Economic Analysis of Symbiotic Light-Water Reactor and Fast Burner Reactor Systems,” INL/EXT-09-15254, Idaho National Laboratory (2009). 